\title{
Dissecting Disease Tolerance in Plasmodium vivax Malaria Using the Systemic Degree of Inflammatory Perturbation
}

1 Short Title: Inflammatory Tolerance to Plasmodium vivax Infection

2 Caian L. Vinhaes ${ }^{1,2,3 \#}$, Thomas A. Carmo, ${ }^{1,2,4}$, Artur T. L. Queiroz ${ }^{1,2}$, Kiyoshi F.

3 Fukutani ${ }^{1,2,5}$, María B Arriaga ${ }^{1,2,6}$, Marcus V. G. Lacerda ${ }^{7,8}$, Manoel Barral-

4 Netto $^{1,6,9}$ and Bruno B. Andrade ${ }^{1,2,3,4,5,6 *}$

5 '1nstituto Gonçalo Moniz, Fundação Oswaldo Cruz (FIOCRUZ), Salvador 40296-710,

6 Brazil;

$7 \quad{ }^{2}$ Multinational Organization Network Sponsoring Translational and Epidemiological

8 Research (MONSTER) Initiative, Salvador 41810-710, Brazil

$9 \quad{ }^{3}$ Escola Bahiana de Medicina e Saúde Pública (EBMSP), Salvador 40290-000, Brazil

$10{ }^{4}$ Curso de Medicina, Universidade Salvador (UNIFACS), Laureate Universities,

11 Salvador 41.720-200, Brazil

$12{ }^{5}$ Curso de Medicina, Centro Universitário Facultade de Tecnologia e Ciências

13 (UniFTC), Salvador 41741-590, Brazil

$14{ }^{6}$ Faculdade de Medicina, Universidade Federal da Bahia, Faculdade de Medicina,

15 Salvador 40110-100, Brazil

$16{ }^{7}$ Instituto de Pesquisa Clínica Carlos Borborema, Fundação de Medicina Tropical Dr

17 Heitor Vieira Dourado, Manaus 69040-000, Brazil

18 Instituto Leônidas \& Maria Deane, Fundação Oswaldo Cruz, Manaus 69057-070,

19 Brazil

$20{ }^{9}$ Instituto Nacional de Ciência e Tecnologia, Instituto de Investigação em Imunologia,

21 São Paulo 05403-900, Brazil

22 \#These authors shared first authorship on this work.

23 *Corresponding author: bruno.andrade@ fiocruz.br (BBA)

24 Keywords: malaria, Plasmodium Vivax, inflammation, molecular degree of

25 inflammatory imbalance, biomarkers 


\section{Abstract}

28 Homeostatic perturbation caused by infection fosters two major defense stratagems, 29 resistance and tolerance, which promote the host's survival. Resistance relates to the 30 ability of the host to restrict the pathogen load. Tolerance minimizes collateral tissue 31 damage without directly affecting pathogen fitness. These concepts have been explored 32 mechanistically in murine models of malaria but only superficially in human disease.

33 Indeed, individuals infected with Plasmodium vivax may present with asymptomatic 34 malaria, only mild symptoms, or be severely ill. We and others have reported a diverse 35 repertoire of immunopathological events that potentially underly susceptibility to 36 disease severity in vivax malaria. Nevertheless, the combined epidemiologic, clinical, 37 parasitological, and immunologic features associated with defining the disease 38 outcomes are still not fully understood. In the present study, we perform an extensive 39 outlining of cytokines and inflammatory proteins in plasma samples from a cohort of 40 individuals from the Brazilian Amazon infected with $P$. vivax and presenting with 41 asymptomatic $(n=108)$ or symptomatic $(n=134)$ disease (106 with mild presentation and 4228 with severe malaria), as well as from uninfected endemic controls $(n=128)$ to 43 elucidate these gaps further. We employ highly multidimensional Systems Immunology 44 analyses using the molecular degree of perturbation to reveal nuances of a unique 45 profile of systemic inflammation and imbalanced immune activation directly linked to 46 disease severity as well as with other clinical and epidemiologic characteristics. The 47 findings mapped the relationships between the systemic degree of inflammatory 48 perturbation and parasitemia values to define the disease tolerance in vivax malaria. 


\section{Author Summary}

52 Plasmodium vivax infection can result in a broad spectrum of disease manifestations, 53 ranging from asymptomatic malaria to severe life-threatening disease. Despite 54 significant advances in the current understanding of the critical factors associated with 55 the disease outcomes in vivax malaria, the immunopathological events responsible for

56 the diversity of severe manifestations in the disease remain deeply unknown. Here, a 57 large panel of cytokines/chemokines were assessed in plasma samples from a Brazilian 58 cohort of $P$. vivax patients presenting with asymptomatic infection or symptomatic 59 malaria at the time of diagnosis, as well as from uninfected endemic controls, to define 60 the relationships between systemic inflammation, disease presentation, parasitemia, and 61 epidemiologic characteristics. In-depth analyses using the molecular degree of 62 perturbation were employed to reveal nuances of a unique profile of systemic 63 inflammation and imbalanced immune activation directly linked to disease severity. 64 Moreover, the discoveries diagrammed the occurrence of disease tolerance by 65 narrowing down the interactions between the systemic degree of inflammatory 66 perturbation and parasitemia values in vivax malaria patients. 
medRxiv preprint doi: https://doi.org/10.1101/2021.03.06.21253036; this version posted March 8, 2021. The copyright holder for this preprint (which was not certified by peer review) is the author/funder, who has granted medRxiv a license to display the preprint in perpetuity.

It is made available under a CC-BY-NC 4.0 International license.

\section{Introduction}

69 Malaria remains a major global cause of morbidity and mortality, with devasting impact over the last 10 years, estimated by more than 200 million cases and 400,000 deaths reported per year worldwide [1]. In contrast to the burden of Plasmodium falciparum

72 infection in African countries, Plasmodium vivax represents the predominant parasite in 73 American regions, with noticeable incidence within the Brazilian Amazon, responsible 74 for the vast majority of malaria cases in this area [1,2]. Also, infection with $P$. vivax is 75 historically thought to result in milder disease presentation than that caused by $P$. 76 falciparum, mostly because the latter commonly results in high parasitemia, intense 77 hemolysis and inflammation associated with cytoadherence to small capillaries 78 (reviewed in [3]). Nevertheless, more recently, several clinical and immunologic reports have revealed that $P$. vivax infection can clearly result in severe clinical presentations such as respiratory distress and acute kidney failure [4-6]. The exact immune mechanisms that underly susceptibility to infection and disease severity upon infection with $P$. vivax are not yet fully understood. We and others have described that older individuals who live for many years in a highly endemic area, and those who are highly exposed and had several previous malaria episodes, tend to develop asymptomatic $P$. vivax infection, which is associated with very low parasitemia and diminished inflammatory responses [7]. Furthermore, a broad spectrum of disease manifestations may occur among those who get sick, ranging from oligosymptomatic condition to multi-organ damage [8]. Understanding the molecular determinants of disease severity may help develop improved prophylactic and therapeutic strategies and optimize patient care.

91 The capacity to restrict the infection burden and control inflammation and immune 92 activation are major determinants of the malaria clinical outcomes (reviewed in $[9,10]$ ).

93 The ability to control parasite load results from anti-microbial immune responses and 94 leads to pathogen elimination and resistance to infection [11]. Exacerbated anti-parasite immune responses promote oxidative stress and inflammatory burst, which in turn cause collateral tissue injury, named immunopathology [12]. In this scenario, the capability to minimize organic damage without directly influencing the infection burden or pathogen fitness is a critical survival strategy defined as disease tolerance $[10,11,13-15]$. In the

99 context of malaria, disease tolerance is present in highly exposed individuals from 100 endemic regions, where subjects may harbor a wide range of detectable parasitemia 
101 levels without exhibiting severe clinical manifestations [16-18]. Findings from previous

102 investigations support the idea that disease tolerance in malaria may occur as

103 modulation of pro-inflammatory responses and dendritic cell function [19,20].

104 Furthermore, in experimental malaria models, control of the collateral tissue damage

105 occurs through tightly regulated mechanisms such as glucose and iron metabolism,

106 renal control, and adrenal hormones [15,21-23]. In humans, we have previously

107 reported that metabolic adaptation to iron overload through induction of ferritin confers

108 tolerance to P. vivax malaria [15]. Despite the substantial advance in the knowledge

109 about the relevant determinants of tolerance to malaria, especially in murine models, to

110 our knowledge no detailed characterization of the systemic inflammation and immune

111 activation profiles related to this host defense strategy has been reported in P. vivax

112 malaria. Here, we aimed to analyze the degree of systemic inflammatory imbalance in

113 P. vivax patients from the Brazilian Amazon. We have compared individuals with

114 asymptomatic, mild, or severe symptomatic disease, to define the complexity and

115 multifactorial regulation subjacent to the malaria immunopathogenesis and the

116 responses underlying the disease tolerance. To do that, we employed a recently reported

117 approach named the molecular degree of inflammatory perturbation [24-28] using

118 concentrations of a large panel of cytokines, chemokines, growth factors and acute

119 phase proteins in peripheral blood at the time of malaria diagnosis. The findings from

120 our in-depth analyses support the idea that disease tolerance in $P$. vivax malaria is a

121 tightly regulated process that integrates features highly influenced by age, previous

122 malaria episodes, and a coordinated regulation of the systemic concentrations of

123 mediators of inflammation.

\section{Materials and Methods}

\section{Ethics Statements}

128 Written informed consent was obtained from all participants or their legally responsible 129 guardians, and all clinical investigations were conducted according to the principles 130 expressed in the Declaration of Helsinki. The project was approved by the institutional 
medRxiv preprint doi: https://doi.org/10.1101/2021.03.06.21253036; this version posted March 8, 2021. The copyright holder for this preprint (which was not certified by peer review) is the author/funder, who has granted medRxiv a license to display the preprint in perpetuity.

It is made available under a CC-BY-NC 4.0 International license .

131 review board of the Faculdade de Medicina, Faculdade São Lucas, Rondônia, Brazil,

132 where the study was performed (protocol no. AP/CEP/55/07).

\section{Study Design}

134 We performed multidimensional retrospective analysis of a databank containing 135 clinical, epidemiological and immunological data from 530 individuals from the 136 Brazilian Amazon (Rondônia, Brazil) recruited between 2006 and 2007, as part of a 137 project aimed at describing determinants of susceptibility to vivax malaria that was 138 finalized in 2010. In this project, both active and passive malaria case detection were 139 performed. These included home visits in areas of high transmission (active case 140 detection), and study of individuals seeking care at the diagnostic centers of Brazilian 141 National Foundation of Health (FUNASA) or in a municipal hospital in Buritis, 142 Rondônia, Brazil (passive case detection) [6,29,35,39,50-53]. Diagnosis, recruitment 143 details and clinical definitions were previous published [15,29,35,50-54]. To direct test 144 the effects of $P$. vivax infection in the molecular degree of perturbation only patients 145 with $P$. vivax monoinfection ( $\mathrm{n}=242$, from those 108 were classified as asymptomatic 146 and 134 symptomatic participants) and healthy controls $(n=128)$ were included. The 147 exclusion criteria for the present study were: $P$. falciparum infection documented by 148 both microscopy and nested polymerase chain reaction (PCR), HIV-1, hepatitis B and C 149 infection, yellow fever, leptospirosis, tuberculosis, cutaneous leishmaniasis, diabetes 150 mellitus, allergic diseases as asthma, cancer, chronic degenerative diseases, sickle cell 151 trait and the use of hepatotoxic or immunosuppressant drugs. Blood collection for 152 nested polymerase chain reaction (PCR) and other measurements (cytokines, 153 chemokynes, hepatic enzymes, creatinine, fibrinogen, bilirubin levels, free heme and 154 haptoglobin) were performed at the time of study enrollment, meaning that specimens 155 were collected at diagnosis, during acute phase of disease in symptomatic patients, 156 before treatment initiation. Individuals without symptoms were actively recruited in 157 their residencies by active search, mostly in remote riverine communities and had thick 158 blood smear samples and a small aliquot of blood in EDTA tubes collected for 159 diagnostic screening by nested PCR. The diagnosis in those individuals was performed 160 after the clinical visit and if a positive test for malaria was found, a second visit within 16130 days was performed in order to search for appearance of malaria symptoms. A new 162 sample collection was made, and a second round of diagnostic tests was performed. 163 Subjects that remained with positive nested PCR for Plasmodium within this period of 
medRxiv preprint doi: https://doi.org/10.1101/2021.03.06.21253036; this version posted March 8, 2021. The copyright holder for this preprint (which was not certified by peer review) is the author/funder, who has granted medRxiv a license to display the preprint in perpetuity.

It is made available under a CC-BY-NC 4.0 International license.

16430 days and presented no malaria-related symptoms, such as fever (axillary temperature $165>37.8^{\circ} \mathrm{C}$ ), chills, sweats, myalgia, arthralgia, strong headaches, nausea, vomiting, 166 jaundice, and severe asthenia during this period were considered as asymptomatic 167 malaria cases. During the first clinical visit (previously to the results of the diagnostic 168 tests) all the asymptomatic individuals received counselling and were oriented to seek 169 for health care in a malaria reference center in case symptoms appeared during the 170 period between the 2 clinical visits. After the second clinical visit, all the patients that

171 had positive malaria screening with microscopy and/or nested PCR were treated 172 following the treatment guidelines of the Brazilian Ministry of Health. The plasma 173 samples used to assess the biomarkers were collected during the second clinical visit, 174 before the initiation of anti-malarial drugs, as previous described [39]. Clinical, 175 demographic and epidemiological characteristics of the study participants were included 176 in S1 Table. Considering the absence of a consensus to define severe vivax malaria, 177 here we used a previous adapted criterion based on P. falciparum infection, as 178 previously published by our group [6,35]. Raw data used in all the analyses are 179 concatenates in S1 File.

\section{Laboratory Measurements}

181 Plasma levels of cytokines interleukin (IL)1- $\beta$, IL-4, IL-6, IL-10, IL-12p70, interferon 182 (IFN)- $\gamma$, tumor necrosis factor (TNF)- $\alpha$, and of C-C motif chemokine ligand (CCL)2, 183 CCL5, C-X-C motif chemokine ligand (CXCL)9, and CXCL10 were measured using 184 the Cytometric Bead Array - CBA ${ }^{\circledR}$ (BD Biosciences Pharmingen, San Diego, CA, 185 USA), according to the manufacturer's protocol. The measurements of aspartate amino186 transferase (AST), alanine amino-transferase (ALT), total bilirubin, direct bilirubin, 187 creatinine, fibrinogen and C-reactive protein (CRP) were performed at the Pharmacy 188 School of the Federal University of Bahia and at the clinical laboratory of Faculdade 189 São Lucas, Brazil.

\section{Adaptation of Molecular Degree of Perturbation}

191 The molecular inflammatory perturbation is based on the molecular degree of 192 perturbation (MDP) method, used and recently published by our group [24-28]. In the 193 present study, we inputted the plasma concentrations of a defined set of biomarkers 194 based on previously published studies from our group in malaria pathogenesis $195[15,29,35,50-54]$. Thus, herein, the average plasma concentration levels and the 
196 standard deviation of a baseline reference group (endemic controls) were calculated for

197 each biomarker. The MDP score of an individual biomarker was defined by taking the

198 differences in concentration levels from the average of the biomarker in the reference 199 group divided by the reference standard deviation. Essentially, the MDP score 200 represents the difference, by number of standard deviations, from the healthy control 201 group. The equation used to calculate MDP in the present study is shown below:

$\mathrm{n}=$ Number of data points

$$
\begin{gathered}
\text { Molecular degree of perturbation }=\frac{x_{i}-\bar{x}_{(\text {reference })}}{\sigma_{(\text {reference })}} \\
\sigma=\frac{\sum_{i=1}^{n}\left(x_{i}-\bar{x}\right)^{2}}{n-1}
\end{gathered}
$$

$203 x i=$ Each of the value of data

$204 \mathrm{x} \square=$ Mean of the data points

$205 \sigma=$ Standard deviation

206 In this study we applied the MDP scoring system using data on 21 biomarkers measured

207 from three distinct groups of patients, with symptomatic vivax infection, asymptomatic

208 vivax infection and uninfected endemic controls. The MDP was filtered by the absolute

209 MDP scores below 2 modules and by the sum of all accumulated MDP deviations. To

210 identify samples implicated in 'perturbation', all values above the cutoff of the average

211 MDP score plus 2 standard deviations of the reference group were considered

212 "perturbed". In additional analyses, the median value of ssMDP in symptomatic patients

213 was calculated (value=48.11), and individuals exhibiting values above this threshold

214 (top 50\% symptomatic participants) were considered highly perturbed.

\section{Statistical Analysis}

216 Descriptive statistics were performed to characterize the study population. Continuous

217 variables were tested for Gaussian distribution using the D'Agostino-Pearson test. No

218 variables exhibited normal distribution. The median values with interquartile ranges

219 were used as measures of central tendency and dispersion, respectively. The Kruskal-

220 Wallis test with the Dunn's multiple-comparison were used to compare continuous

221 variables whereas the Pearson's chi-square test was used to compare variables displayed

222 as percentages. Hierarchical cluster analyses (Ward's method) of $\log 10$ transformed and

223 z-score normalized data were employed to depict the overall expression profile of

224 indicated biomarkers in the study subgroups. All comparisons were pre-specified and 
medRxiv preprint doi: https://doi.org/10.1101/2021.03.06.21253036; this version posted March 8, 2021. The copyright holder for this preprint (which was not certified by peer review) is the author/funder, who has granted medRxiv a license to display the preprint in perpetuity.

It is made available under a CC-BY-NC 4.0 International license .

225 two-tailed. Differences with p-values below 0.05 after Holm-Bonferroni's adjustment

226 for multiple comparisons were considered statistically significant. Profiles of correlation

227 between biochemical parameters were examined using network analysis of the

228 Spearman correlation matrices. Correlations with p-value $<0.05$ were included in the

229 network visualization. Spearman rank values (rho) were used to describe the strength of

230 correlations between viral load from participants with current chronic infection and the

231 MDP score of inflammatory parameters of these participants.

232 A Kaplan-Meier curve adaptation [33] was employed to test the probability of being

233 highly perturbed according to the number of previous malaria episodes and age. A

234 discriminant model using sparse canonical correlation analysis (CCA) was employed to

235 assess whether inflammatory biomarkers, tissue damage biomarkers and inflammatory

236 and tissue damage biomarkers could characterize the symptomatic participants. One

237 polynomic (multinomial) logistic regression model was carried out using the variables

238 with P-value <0.02 in the Mann-Whitney test between symptomatic and asymptomatic

239 vivax participants, as showed in Table S1, to detect variables, epidemiologic or

240 laboratorial, associated with symptomatic diseases.

241 Based on the mathematic formulas employed to visualize space-time deformity based

242 on the general relativity theory proposed by Albert Einstein in 1915, we adapted the

243 application of the proposed model to assess the overall impact of variables used here on

244 homeostasis (defined as space-time membrane). In this model, homeostasis was defined

245 by a plain p-brane which may be subjected to different degrees of deformities

246 depending on the perturbation (distance from normal, which is calculated through the

247 MDP scores) caused by each inflammatory marker, tissue damage markers and from the

248 pathogen itself (parasitemia). The calculations and plots were build using the package

249 Shapes from R.

250 The statistical analyses were performed using GraphPad Prism 8.0 (GraphPad Software,

251 La Jolla, CA, USA), JMP 14.0 (SAS, Cary, NC, USA) and R statistical software. 
medRxiv preprint doi: https://doi.org/10.1101/2021.03.06.21253036; this version posted March 8, 2021. The copyright holder for this preprint (which was not certified by peer review) is the author/funder, who has granted medRxiv a license to display the preprint in perpetuity.

It is made available under a CC-BY-NC 4.0 International license .

\section{Results}

\section{Characteristics of Study Population}

254 Overall, study participants with symptomatic malaria were significantly younger when 255 compared with those with asymptomatic $P$. vivax infection or uninfected controls 256 (median age 29 [IQR 19-42]; 44 [IQR 34-50]; 39 [IQR 25-50] years, respectively, $257 \mathrm{P}<0.001)$. No differences were noted in regard to sex distribution $(\mathrm{P}=0.43)$. Of note, 258 individuals with asymptomatic malaria referred a higher number of previous malaria 259 episodes $(100 \%, \mathrm{P}<0.001)$. Also, statistical discrepancies were found in the time living 260 in the endemic area, with, on average, fewer years reported by symptomatic patients 261 (P<0.001). Noteworthy, the vast majority of MDP values calculated with the biomarkers 262 measured in the study exhibited significant differences among groups. Additional 263 findings are detailed in the S1 Table. Using a multivariate analysis, based on a stepwise 264 model (as described in Methods), we confirmed that aging, presenting with more than 265 ten years living in endemic area and increased number of previous malaria episodes 266 were protective factors against occurrence of symptoms during the current malaria 267 episode in the adjusted model, whereas the increases in the global inflammatory 268 disturbance, measured by ssMDP, was a factor independently associated with the 269 symptomatic malaria (S1 Figure panel A).

270 Patients with symptomatic vivax malaria exhibit a higher degree of systemic 271 inflammatory perturbation

272 To assess potential differences in the inflammatory activation according to the presence 273 or absence of symptoms in vivax infection, we employed the molecular degree of 274 perturbation (MDP, as described in Methods) in each study subpopulation (Fig 1).

275 Individuals presenting with symptomatic vivax malaria exhibited higher ssMDP score 276 values than those with asymptomatic infection or the uninfected control groups (Figs 277 1A and 1B). In addition, ssMDP values were also higher in asymptomatic malaria 278 individuals than in those from the endemic control group (Fig 1B). These results 279 reinforce the idea that the presence of $P$. vivax infection is associated with overall 280 disturbances in the systemic inflammatory profile which degree is proportional to the 281 clinical presentation.

282 Figure 1: Higher degree of inflammatory perturbation associated with symptomatic vivax malaria. (A) 283 Histograms show the molecular degree of perturbation (MDP) score values relative to each study group, 
as indicated. (B) Box plots represent the MDP score distribution between study groups, with median and interquartile range values. Data were compared between the clinical groups using the Kruskal-Wallis test, with Dunn's multiple comparisons ad hoc test. (C) Left panel: Median MDP values for each indicated parameter were $\log 10$ transformed and z-score normalized. A two-way hierarchical cluster analysis (Ward's method) was employed to depict overall trends in changes of the MDP values among the clinical groups. Dendrograms represent the Euclidean distance. Right panel: Average fold-difference values of the MDP scores for each marker were calculated between clinical groups. Green bars represent statistically significant differences estimated by the Mann-Whitney $\mathrm{U}$ test. P-values were adjusted for multiple comparisons using the Holm-Bonferroni method. Abbreviations (alphabetic order): ALT: alanine aminotransferase; AST: aspartate aminotransferase; CCL: C-C motif chemokine ligand; CXCL: C-X-C motif chemokine ligand; CRP: C-reactive protein; IFN: interferon; IL: interleukin; TNF: tumor necrosis factor.

We next evaluated whether the degree of inflammatory perturbation calculated for each marker could provide more granularity about the disease endotypes' details. The mean MDP score values of each marker of inflammation were analyzed by an unsupervised hierarchical cluster. Using this approach, we identified two main clusters of markers (Fig 1C). The markers forming the first cluster tended to increase the MDP values in the group of symptomatic malaria, with remarkable high values of TNF- $\alpha$, IL-6, CXCL9, AST, CRP, IL-8 and ALT. The second cluster of markers was composed by IFN- $\gamma$, creatinine, IL-1 $\beta$, direct and indirect bilirubin, CXCL10 and IL-10, with heightened MDP values being observed in both the group of individuals with either asymptomatic or symptomatic malaria. Patients with symptoms had the highest levels, except for IL10, which was higher in the asymptomatic malaria group. An additional analysis using a binary multivariate logistic regression model revealed that increased perturbation scores of IL-6, IL-8 and CRP were independently associated with occurrence of symptomatic malaria, whereas higher degree of perturbation of IL-10 and fibrinogen were protective factors against symptoms in $P$. vivax infection (S1 Figure panel B). The visual differences detected in the heatmap of the MDP values were confirmed using folddifference calculations between the study groups (Fig. 1C). Likewise, when comparing symptomatic with the uninfected control group, only perturbations of haptoglobin, creatinine and IL-1 $\beta$ were not significantly increased. The magnitude of differences in the MDP of the individual markers was found to be lower between the groups of individuals with asymptomatic malaria or uninfected controls. Alternatively, although the majority of markers with significant perturbances were noted in symptomatic patients, the comparison of malaria groups also identified augmented expression of MDP levels of IL-10 and indirect bilirubin in asymptomatic individuals. These findings confirm that susceptibility to $P$. vivax malaria's susceptibility may be reflected by 
medRxiv preprint doi: https://doi.org/10.1101/2021.03.06.21253036; this version posted March 8, 2021. The copyright holder for this preprint

(which was not certified by peer review) is the author/funder, who has granted medRxiv a license to display the preprint in perpetuity.

It is made available under a CC-BY-NC 4.0 International license .

321 disturbances in the concentrations of several markers involved in controlling systemic

322 inflammation.

323

324 Network analysis of inflammatory balance in Plasmodium vivax infection

325 To more precisely characterize the nuances and dynamicity of the systemic

326 inflammatory perturbation detected in the presence of $P$. vivax malaria, and which was

327 more pronounced in those with symptomatic infection, we employed a network analysis

328 of MDP values (Fig 2), as previously published by our group in a series of other

329 pathological conditions [24-28].

330

331

332

333

334

335

336

337

338

339

340

Figure 2: Network analysis of the MDP score values in the study groups. Spearman correlation matrices of the MDP score values in each study group - (A) controls; (B), asymptomatic vivax malaria; (C) symptomatic vivax malaria - were built and Circos plots were used to illustrate the correlation networks. Only significant correlations ( $\mathrm{p}<0.05$ after adjustment for multiple comparisons) are shown. Each circle represents a different plasma parameter, and the size of each circle is proportional to the number of significant correlations. Lines represent the Spearman rank (rho) values. Red color infers positive correlation, whereas blue color denotes negative correlation. Node analysis heatmap shows the number of statistically significant correlations involving each marker per clinical group. Abbreviations (alphabetic order): ALT: alanine aminotransferase; AST: aspartate aminotransferase; CCL: C-C motif chemokine ligand; CXCL: C-X-C motif chemokine ligand; CRP: C-reactive protein; IFN: interferon; IL: interleukin; TNF: tumor necrosis factor.

341 Using MDP scores for each biomarker, as well as the overall MDP score (ssMDP), we 342 found an important discrepancy in the network densities among the study groups. The 343 group of symptomatic vivax participants exhibited the highest network density whereas 344 asymptomatic infection displayed the lowest (Fig 2). Moreover, regardless of the 345 clinical groups, most correlations were positive, meaning that increases in inflammatory 346 perturbation of a given marker were frequently followed by increases in the disturbance 347 levels of other inflammatory molecules (Fig 2). Curiously, the interferon pathway 348 dominated the interactions (e.g., statistically significant correlations) in the control 349 group, with CCL2, CXCL9, CCL5, CXCL10, IFN- $\gamma$ and IL-4 showing up as the top 350 highly connected markers (Fig 2A). In the group of asymptomatic malaria participants, 351 the Spearman correlation matrices revealed a unique negative correlation, between the 352 MDP values of CXCL10 and IL-12p70. The most highly connected markers were CRP, 353 CCL2, CCL5, CXCL10, IL-1 $\beta$ and IL-4 (Fig 2B). Importantly, in the group of 354 symptomatic vivax, we found two clusters of correlations: the first composed mainly by 355 interactions between the inflammatory markers and ALT and AST; and the second 356 composed by tissue damage markers (Fig 2C). Next, to verify the individual 
contribution to the global inflammatory perturbation, we employed a Spearman

correlation between the ssMDP and the MDP level of each marker and found that the symptomatic group presented a higher number of significative markers associated with symptoms in vivax malaria is associated with an intense disruption of the homeostasis,

362 hallmarked by an increased overall degree of molecular perturbation as well as by a

363 regulated process hallmarked by an intricate network of correlations of the individual 364 markers.

367 We have previously demonstrated that persons living in malaria endemic areas from the Brazilian Amazon for more than 10 years tend to exhibit increased odds of developing asymptomatic malaria once infected with $P$. vivax [29]. Such findings agree with other investigations on $P$. falciparum infection in other regions of the globe [30,31]. Here, to evaluate the impact of the time of residency in an endemic area on the molecular degree of inflammatory perturbation, we stratified the study participants in two groups: (i) one including those who lived less than ten years and (ii) a second group with persons who referred living more than ten years (Fig 3).

Figure 3: Patients with Plasmodium vivax malaria living longer in the endemic area display an attenuated systemic inflammatory disturbance. (A) Left panel: to build the heatmap, data were log-transformed and z-score normalized. A one-way hierarchical cluster analysis (Ward's method) was employed to show the profiles of the molecular degree of perturbation of participants according to time living in an endemic area (patients were ordered according to time living in an endemic area). Patients were divided in two groups based on time living in the area (those who have lived for less than 10 years or for more than 10 years) and whether they presented with symptomatic or asymptomatic malaria. Right panel: Spearman rank test was used to assess correlations between the individual MDP score values of each parameter or parasitemia and time living in an endemic area (in years). Bars indicate the Spearman coefficient (rho) values. Green bars to the right indicate positive whereas to the left denote negative correlations with adjusted P-values $<0.05$. Grey bars indicate non-significant correlations. (B) The Pearson's chi-square test was used to compare the frequency (percentage) of symptomatic and asymptomatic malaria participants according to the years living in an endemic area. (C) A violin plot was used to show the number of symptoms in the participants stratified according to years living in an endemic area. Data were compared using the Mann-Whitney $\mathrm{U}$ test. Abbreviations (alphabetic order): ALT: alanine aminotransferase; AST: aspartate aminotransferase; CCL: C-C motif chemokine ligand; CXCL: C-X-C motif chemokine ligand; CRP: C-reactive protein; IFN: interferon; IL: interleukin; TNF: tumor necrosis factor.

393 A hierarchical cluster analysis built upon a heatmap of z-score normalized MDP data on 394 each individual marker and $P$. vivax parasitemia values failed to show a profile that 395 could distinguish the individuals based on time living in the endemic area in both 

of $P$. vivax-infected individuals. Interestingly, the MDP scores from most of the markers as well as the parasitemia values were all negatively correlated with time living in the endemic area. One exception was IL-10 MDP values, which were positively correlated with time living in the area (Fig 3A, right panel). Of note, the perturbation of the liver damage parameters ALT, AST, total bilirubin, and also MDP values of IL-4, IL-6, IL-8, IL-12p70, CXCL9, CCL5, CCL2, CRP, fibrinogen and parasitemia levels showed an inverse correlation with the time living in the endemic area. Moreover, an expressive greater number of individuals with asymptomatic malaria was found to live more than 10 years in the area (Fig. 3B). Tolerance to malaria is tightly related to number of previous Plasmodium infections [20,32] and people living for an extended time in endemic regions may be a higher odds of experiencing a higher number of $P$. vivax infections. We then tested whether time living in the endemic area would reflect the number of $P$. vivax symptoms. As expected, individuals living for longer periods in the endemic areas showed a lower number of symptoms in the current malaria episode. (Fig $3 \mathrm{C})$.

Impact of repetitive malaria episodes in the past on the degree of inflammatory perturbation in the current Plasmodium vivax infection

We next directly tested the hypothesis that individuals highly exposed to $P$. vivax and who experienced several previous malaria episodes would gradually learn how to modulate the immune activation and control the inflammatory responses that result in immunopathology, reducing the odds of developing more severe clinical presentations during the current infection. Initially, using Spearman correlation analysis, we found a general tendency to detect a negative correlation between the number of previous vivax malaria episodes and the MDP values of nearly all the markers evaluated (Fig 4A).

Figure 4: Heightened number of previous malaria episodes mitigates the inflammatory imbalance in the current Plasmodium vivax infection. (A) Spearman correlation between the number of previous malaria episodes and the global degree of inflammatory perturbation (ssMDP) of each parameter's individual MDP values. Bars represent the Spearman rank coefficient value (rho). Colored bars (each clinical group is represented by a different color) infer correlations that presented adjusted P-value $<0.05$. (B) A scatter plot was employed to show the correlation between the number of previous malaria episodes and the ssMDP score values. (C) Probability of being highly perturbed ( $>2$ standard deviations from control group) according to the number of previous malaria episodes in all participants (left panel) and participants grouped based on biological sex. The curves were compared using the Steger Method. 
432 Abbreviations (alphabetic order): ALT: alanine aminotransferase; AST: aspartate aminotransferase; CCL:

433 C-C motif chemokine ligand; CXCL: C-X-C motif chemokine ligand; CRP: C-reactive protein; IFN:

434 interferon; IL: interleukin; TNF: tumor necrosis factor.

435 Applying this analysis to all participants with malaria, we observed that only MDP

436 levels of IL-10 were directly associated with the number of previous malaria episodes

437 (Fig 4A). An interesting finding was the negative correlation between the number of 438 previous episodes and parasitemia in all the participants with vivax malaria, 439 independent of the presentation of symptoms (Fig 4A). In participants with

440 symptomatic malaria, only negative correlations were detected, highlighting the 441 influence of previous infection episodes on reducing perturbance of tissue damage 442 markers, such as direct and indirect bilirubin, creatinine, and fibrinogen. This 443 observation reinforces the idea that having a history of several previous Plasmodium 444 vivax infections is related to a relative control of tissue damage (Fig 4A). Extending the 445 approach to asymptomatic participants, we detected a unique inverse correlation 446 between the number of previous episodes and IL-12p70 MDP values. Additionally, we 447 found that even in the uninfected control group, history of previous malaria episodes 448 was associated with reduced perturbation of indirect bilirubin, total bilirubin, CCL2, 449 CXCL10, IL-10 and IFN- $\gamma$ (Fig 4A). Importantly, when all malaria participants were 450 analyzed, the global perturbation measured by ssMDP levels was lower proportionally 451 relative to the number of previous malaria episodes (Figs 4A and 4B). Finally, a 452 Kaplan-Meier survival curve demonstrated that increases in the number of previous 453 malaria episodes resulted in a gradual lower probability of a study participant being 454 considered highly perturbed (presenting with $\geq \pm 2$ SD of the overall ssMDP score value, 455 as described in Methods), independent of biological sex (Fig 4C). Noteworthy, our 456 analysis revealed that previous exposure to Plasmodium infections indeed seems to 457 attenuate the immune activation of the current episode, reflecting the lower odds of 458 experienced an unfettered, unbalanced, inflammatory response.

\section{Aging impacts the molecular degree of perturbation in Plasmodium vivax infection}

460 We have previously suggested that there is an effect of aging in the modulation of 461 systemic inflammation in P. vivax infection [7]. Here, we tested whether such an effect 462 may be explained by the impact of aging on the molecular degree of inflammatory 463 perturbation. Hence, Spearman correlation analysis revealed that, in general, increasing 
medRxiv preprint doi: https://doi.org/10.1101/2021.03.06.21253036; this version posted March 8, 2021. The copyright holder for this preprint (which was not certified by peer review) is the author/funder, who has granted medRxiv a license to display the preprint in perpetuity.

It is made available under a CC-BY-NC 4.0 International license.

464 in age was associated with decreases in the MDP score values of the markers 465 investigated in the study population (Fig 5).

466 Figure 5: Aging is associated with diminished systemic inflammatory disturbance in vivax malaria. (A) Spearman correlation between age and the global degree of inflammatory perturbation (ssMDP) of the

468 individual MDP values for each parameter. Bars represent the Spearman rank coefficient value (rho).

469 Colored bars (each clinical group is represented by a different color) infer correlations that presented

470 adjusted P-value <0.05. (B) A scatter plot was employed to show the correlation between age and the

471 ssMDP score values. (C) Probability of being highly perturbed ( $>2$ standard deviations from the control 472 group) according to age in all participants (left panel) and in participants grouped based on biological sex.

473 Abbreviations (alphabetic order): ALT: alanine aminotransferase; AST: aspartate aminotransferase; CCL:

474 C-C motif chemokine ligand; CXCL: C-X-C motif chemokine ligand; CRP: C-reactive protein; IFN: 475 interferon; IL: interleukin; TNF: tumor necrosis factor.

476 Considering only vivax participants, all the statistically significant correlations between 477 aging and MDP score values were negative, meaning that increases in age were directly 478 related to a reduction in the global inflammatory disturbance (ssMDP), in the individual 479 degree of perturbation of fibrinogen, ALT, AST, TNF- $\alpha$, IFN- $\gamma$, haptoglobin and also 480 parasitemia (Fig 5A). Importantly, in the group of symptomatic malaria, aging was 481 significantly related to decreased haptoglobin MDP values only, whereas in the group of 482 asymptomatic malaria, aging specifically reduced the fibrinogen MDP values but not of 483 other markers (Fig 5A). In the endemic control group, we found that aging was 484 associated with increases in MDP scores of IL-8 and IL-1 $\beta$ and decreased MDP values 485 of total and direct bilirubin. We next evaluated the impact of aging in the global 486 inflammatory perturbation in all of our study participants and found a negative 487 correlation $(\mathrm{r}=0.011 ; \mathrm{P}=0.032$ ) (Fig 5B). Further, increases in age were shown to 488 proportionally reduce the probability of an individual being highly perturbed regardless 489 of the biological sex (Fig 5C), suggesting that aging mitigates the inflammatory 490 imbalance in P.vivax-infected individuals. Finally, a hierarchical cluster analysis 491 performed based on the age and number of malaria episodes could not distinguish 492 groups when all participants were inputted. However, it reinforced our results exhibiting 493 the influence of aging and previous infections over more controlled inflammatory 494 responses (reduced MDP values) and lower frequency of symptomatic malaria cases (S3 495 Figure). 
498 To dissect the clinical effects of the inflammatory imbalance during $P$. vivax infection, 499 we used a color map analysis, ordinating the participants based on the number of 500 symptoms, to describe the symptomatology distribution in our study population (Fig $6 \mathrm{~A})$.

Figure 6: Impact of systemic inflammatory disturbance on the number of symptoms in Plasmodium vivax malaria. (A) Symptomatic Plasmodium vivax malaria patients were ordered according to the number of symptoms. A color map highlighting the detection of each symptom is shown. Parasitemia $(\log 10)$ and age are shown as continuous variables on the bottom for each patient. (B) Spearman correlation between the number of symptoms and age (left panel) and Log10 parasitemia (right panel). Linear curves with 95\% confidence intervals were used to illustrate trends in data variation. (C) Patients were stratified into three groups based on the presence of symptoms: Asymptomatic, Oligosymptomatic $(\leq 5$ symptoms $)$ or Polysymptomatic ( $>5$ symptoms). Left panel: Median MDP values for each indicated parameter were Log10 transformed and z-score normalized. A one-way hierarchical cluster analysis (Ward's method) was employed to depict overall trends in changes of the MDP values among the clinical groups. Dendrograms represent the Euclidean distance. Right panel: Spearman correlation between the number of symptoms and the MDP score values for each indicated parameter. Green bars indicate statistically significant correlations (all positive after adjusted P-value <0.05). Grey bars denote a non-significant correlation. (D) Violin plot shows the distribution of the global degree of perturbation (ssMDP) in each subgroup of Plasmodium vivax patients. Data were compared using the Kruskal-Wallis test with a non-parametric linear trend posttest.

518 As expected, fever was the main symptom documented in $P$. vivax-infected participants, 519 which was identified in all patients, followed by chills, sweating, headache, myalgia, 520 arthralgia and nausea. We next employed Spearman correlation analyses and found a 521 curious negative correlation between the number of symptoms and both age and 522 parasitemia ( $\mathrm{r}=-0.34, \mathrm{P}<0.001 ; \mathrm{r}=-0.24, \mathrm{P}=0.004$, respectively) (Fig 6B). Next, we 523 divided our participants according to the number of symptoms, in asymptomatic (no 524 symptoms), oligosymptomatic (less than six symptoms) and polysymptomatic (those 525 who presented six or more symptoms) and employed a hierarchical cluster and a 526 Spearman correlation analysis to investigate the potential effect of the inflammatory 527 activation (measured through MDP score values of the markers) on symptomatology in 528 P. vivax infection (Fig 6C). A clear distinction in the MDP profiles of the markers was 529 observed in the unsupervised hierarchical cluster between asymptomatic, 530 oligosymptomatic and polysymptomatic groups (Fig. 6C). Overall, the group of 531 polysymptomatic individuals exhibited relatively heightened inflammatory perturbation 532 values, distinguished from the other groups by expression of almost all markers when 533 compared with asymptomatic participants. Precisely, increased IFN- $\gamma$, IL-1 $\beta$, creatinine, 534 direct and indirect bilirubin MDP scores in comparison with the oligosymptomatic 
medRxiv preprint doi: https://doi.org/10.1101/2021.03.06.21253036; this version posted March 8, 2021. The copyright holder for this preprint (which was not certified by peer review) is the author/funder, who has granted medRxiv a license to display the preprint in perpetuity.

It is made available under a CC-BY-NC 4.0 International license .

535 group (Fig 6C). Asymptomatic participants, on the other hand, showed a tendency to 536 express higher MDP values of IL-10 and CXCL10, which were clearly lower than the 537 oligo and polysymptomatic groups (Fig 6C). Furthermore, Spearman correlation 538 analyses were performed to investigate the association between the number of 539 symptoms and the degree of inflammatory perturbation of the markers indicated. This 540 approach revealed that the number of symptoms was associated mainly with increases 541 in the degree of perturbation of tissue damage markers, such as AST, ALT, total and 542 indirect bilirubin, fibrinogen and creatinine (Fig 6C). Additionally, we found that the 543 global molecular perturbation measured by ssMDP values exhibited a gradual tendency 544 to increase in the participants according to the augmented number of symptoms (Fig 545 6D). Our findings argue that the degree of inflammatory disturbance in peripheral blood 546 of $P$. vivax malaria patients is directly related to the clinical presentation severity.

547 Perturbation in concentrations of tissue damage markers, rather than of immune 548 activation molecules characterizes symptomatic Plasmodium vivax malaria

549 Among the biomarkers investigated in the present study, there were mostly two classes 550 of molecules: (i) those that more closely infer inflammatory activity and (ii) those 551 intrinsically related to tissue damage/injury (Fig 7A).

Figure 7: Using canonical correlation analysis of the degree of perturbation of inflammatory or tissue damage markers to characterize vivax malaria. (A) In an exploratory approach, a sparse canonical correlation analysis (sCCA) was used to test whether the indicated clinical groups could be distinguished based on: (B) the overall perturbation profile of all the markers measured, or combinations of (C) tissue damage markers or (D) inflammatory markers only. Lower panels show the canonical coefficient scores calculated to identify the biomarkers responsible for the distinctions between groups in each sCCA model as indicated. Abbreviations (alphabetic order): ALT: alanine aminotransferase; AST: aspartate aminotransferase; CCL: C-C motif chemokine ligand; CXCL: C-X-C motif chemokine ligand; CRP: Creactive protein; IFN: interferon; IL: interleukin; TNF: tumor necrosis factor.

561 To more precisely define which class of markers is more relevant to explain the 562 occurrence of symptoms in individuals infected with $P$. vivax, we used a discriminant 563 algorithm based on sparse canonical correlation analysis (sCCA). We performed three 564 models (i) one with all the markers (Fig 7B), (ii) a second model with only the tissue 565 damage markers (Fig 7C) and (iii) a final model including only inflammation-related 566 markers (Fig 7D). In all three models, discrimination of symptomatic participants from 567 asymptomatic and endemic controls was detected with a high degree of accuracy (Fig 568 7B-D). As expected, differentiation between asymptomatic malaria and uninfected 569 controls was difficult, with many misclassifications seen in the models. We next 
medRxiv preprint doi: https://doi.org/10.1101/2021.03.06.21253036; this version posted March 8, 2021. The copyright holder for this preprint (which was not certified by peer review) is the author/funder, who has granted medRxiv a license to display the preprint in perpetuity.

It is made available under a CC-BY-NC 4.0 International license .

570 assessed the canonical coefficients of each model, which is a statistical strategy to rank

571 the markers that most contributed to the discriminant model. This approach found that

572 AST and ALT were the top markers associated with symptomatic participants (Fig 7B).

573 In the second model, canonical coefficient values of tissue damage markers, ALT and

574 AST also emerged as the top markers that could identify individuals with symptomatic

575 malaria, whereas direct bilirubin and haptoglobin the top damage markers associated

576 with the distinction between asymptomatic malaria and uninfected controls (Fig 7C).

577 Finally, we used only the inflammatory markers (Fig 7D) and observed a relevant

578 decrease in the discrimination power, with 38 misclassifications in the group of

579 symptomatic malaria. Using information from the canonical coefficients, we found that

580 the IFN pathway showed a relevant role in the discrimination of symptomatic malaria

581 and controls, with CCL2 followed by CXCL10 and CXCL9 as the top markers. CXCL9

582 and IL-4 were the top markers when we analyzed asymptomatic malaria vs. controls,

583 whereas IL-6 and CXCL10 were highlighted when symptomatic vs. asymptomatic

584 malaria patients were compared (Fig 7D). In the context of $P$. vivax malaria, these

585 observations reinforce the idea that alterations in circulating concentrations of tissue

586 damage-associated markers more intrinsically relate with the appearance of symptoms

587 than the imbalance of the immune activation alone.

588 Characterizing disease tolerance in Plasmodium vivax malaria

589 We further tested whether disease tolerance could be observed and characterized in the

590 study participants infected with $P$. vivax. To do so, we examined the systemic

591 inflammation assessed through the ssMDP values in the context of $P$. vivax parasitemia

592 and the number of symptoms. First, we employed a hierarchical cluster with z-score

593 normalized values to depict the overall distribution of these three selected parameters in

594 the group of patients with symptomatic malaria. Interestingly, the combination of the

595 ssMDP, number of symptoms, and $P$. vivax parasitemia was not able to completely

596 segregate patients with severe malaria from those with non-severe malaria (See

597 definitions used to classify patients based on malaria severity in Methods) (Fig 8A).

598

599

600

601

602

603

604
Figure 8: Characterizing disease tolerance in Plasmodium vivax malaria. (A) Left panel: A two-way hierarchical cluster analysis was employed to characterize the overall profiles of parasitemia, systemic inflammatory disturbance (ssMDP) and the number of symptoms in Plasmodium vivax patients presenting with either severe $(n=28)$ or non-severe disease $(n=106)$. Right panel: A Chi-Square test was used to test the proportion of severe vivax patients in each cluster identified. (B) A principal component (PCA) model (left panel) with a vector plot (right panel) was used to demonstrate the influence of each indicated parameter on the distribution of the data. Colors indicate the clusters identified in panel (A). (C) 
605

606

607

608

609

610

611

612

613

614

615

616

617

618

619

620

621

622

623

624

625

626

627

628

629

630

631

632

633

634

635

636

637

638

639

Patients were segregated according to malaria severity and a Spearman correlation analysis was performed to identify the association between parasitemia and number of symptoms ( $\mathrm{N}^{\circ}$ of symptoms). (D) A space-time deformity model based on the relativity theory of gravity was employed to visualize the impact of each plasma marker and tissue damage marker on disturbance of the homeostasis (defined as space-time brane in the control group). See Methods for details on the mathematical model. Each dot represents a marker, and groups of patients were separated based on the cluster analyses shown in (A).

Moreover, the clustering analysis revealed four main clusters of study participants. The first cluster was composed predominantly by patients with non-severe malaria. Such cluster was characterized by the highest parasitemia and variable ssMDP values, with a low number of symptoms (Fig 8A). The second cluster was also composed mainly by non-severe malaria participants and exhibited a relatively low value for all three parameters evaluated (Fig 8A). The third cluster displayed a slight increase in the frequency of participants with severe malaria and was marked by augmented levels of global molecular perturbation, despite lower parasitemia values and the number of symptoms (Fig 8A). Finally, the fourth cluster was constituted by a majority of participants with severe malaria. This latter cluster exhibited more commonly a higher number of symptoms despite the relative lower ssMDP values and parasitemia levels (Fig 8A). These results suggest that the fourth cluster of study participants included less tolerant to $P$. vivax malaria patients. A principal component analysis (PCA), using the same parameters inputted in the hierarchical clustering, validated the idea that the number of symptoms, systemic inflammation assessed by ssMDP, and parasitemia were all independently influencing the distribution of the participants with symptomatic malaria into different subgroups of individuals. The PCA groups were similar to the clusters identified in the clustering analysis (Fig. 8B). Importantly, correlation analyses revealed an inverse linear association between parasitemia and the number of symptoms in individuals with non-severe malaria but not in those with severe malaria (Fig 8C). We next employed statistics previously used to assess space-time deformity by gravity following the general relativity theory (as described in Methods) to visualize the impact of each inflammatory and tissue damage marker on homeostasis disturbance. The disturbance is defined here by comparison to the space-time brane calculated for the uninfected endemic control group. Using this approach, the degree of deformity in the space-time brane infers the degree of homeostatic disturbance. The analyses demonstrated that the fourth cluster of malaria, mainly composed of severe malaria patients, exhibited the highest homeostatic disturbance (Fig 8D). As shown in Fig 8D, there was a progressive disturbance of the homeostasis through clusters 1 to 4 , revealing 
medRxiv preprint doi: https://doi.org/10.1101/2021.03.06.21253036; this version posted March 8, 2021. The copyright holder for this preprint

(which was not certified by peer review) is the author/funder, who has granted medRxiv a license to display the preprint in perpetuity.

It is made available under a CC-BY-NC 4.0 International license .

640 a remarkable tolerance pattern, in which patients from the first cluster exhibited more

641 robust tolerance to the disease.

\section{Identifying the Determinants of Disease Tolerance in $P$. vivax Infection}

643 Spearman correlation matrices between the MDP values of the inflammatory or tissue

644 damage markers and the number of symptoms and parasitemia values were employed to

645 dissect the factors that could directly or indirectly influence tolerance in vivax malaria

646 patients (Fig 9).

647 Figure 9: Identifying the factors associated with disease tolerance in Plasmodium vivax malaria. A 648 Spearman correlation rank matrix analysis was used to identify the specific inflammatory or tissue 649 damage markers which degree of disturbance is associated with parasitemia or number of symptoms (the 650 latter are represented as central spheres in the network graphs) in patients non-severe or severe P. vivax as 651 indicated. Each line represents a statistically significant correlation $(\mathrm{p}<0.05)$ after adjustment for multiple 652 measurements. Among the statistically significant correlations detected, only positive associations were 653 found.

654 In participants with non-severe vivax malaria, our analysis revealed that only MDP 655 levels of IL-1 $\beta$ and IL-4 were positively correlated with parasitemia. MDP levels of 656 IFN- $\gamma$, IL-4, IL-6, CXCL10, CCL5, and liver parameters ASL and ALT showed to be 657 positively correlated with the number of symptoms (Fig 9). Extending our approach to 658 participants with severe malaria, we found that MDP levels of IL-10, IL-12p70, AST, 659 ALT, and indirect bilirubin were directly associated with parasitemia (Fig 9). 660 Importantly, the number of symptoms in those presenting severe vivax infection was 661 associated with increases of several MDP levels of both inflammatory and tissue 662 damage markers. 
medRxiv preprint doi: https://doi.org/10.1101/2021.03.06.21253036; this version posted March 8, 2021. The copyright holder for this preprint (which was not certified by peer review) is the author/funder, who has granted medRxiv a license to display the preprint in perpetuity.

It is made available under a CC-BY-NC 4.0 International license .

\section{Discussion}

664 Knowledge about disease tolerance in humans remains poorly elucidated, in part due to

665 the difficulty of establishing a reliable measure of systemic inflammation. Here, to fill

666 this gap, we used the molecular degree of perturbation (MDP) approach, a statistical

667 tool that led us to infer the global inflammatory status, and which has been recently

668 proposed by our group to help to understand the pathophysiology of a range of

669 infectious and non-infectious diseases [24-27,33,34]. We evaluated the effects of

670 several epidemiological characteristics in inflammatory responses to $P$. vivax, dissecting

671 the disease tolerance to vivax malaria and identifying the molecular factors associated

672 with the phenomenon.

673 Using the MDP, we found that regardless of the symptomatology, $P$. vivax infected

674 participants exhibited a higher degree of inflammatory perturbation than the control

675 groups. Importantly, symptomatic patients displayed the highest global MDP scores. In

676 fact, we have previously reported that the clinical manifestation in $P$. vivax infection

677 was strongly associated with an inflammatory imbalance in peripheral blood [35]. Here,

678 we also identified a non-surprising pattern of inflammatory imbalance present in all the

679 infected participants. Such a pattern comprises a higher degree of perturbation of

680 CXCL9, CXCL10, IL-8, IL-10, IFN- $\gamma$, AST, ALT, CRP, Fibrinogen, direct and indirect

681 bilirubin concentrations. Moreover, only infected symptomatic patients had TNF- $\alpha$,

682 total bilirubin, and IL-6 increased perturbation. These biomarkers have been extensive

683 explored in the context of malaria pathophysiology. IFN- $\gamma$ and CRP have been recently

684 identified as an inflammatory signature associated with a higher risk of mortality in $P$.

685 vivax infection[6]. Polymorphisms in TNF- $\alpha$ and IL-6 genes [36], as well higher levels

686 of these markers and of CXCL10 [37] were linked to malaria clinical outcomes and pro-

687 inflammatory activation in response to $P$. vivax [38]. IL-10 has a fundamental role in

688 response to Plasmodium infections, directly affecting dampening the inflammation-

689 driven cytokine storm, modulating the immune response, and limiting the tissue

690 damage, reducing odds of severe malaria [39-41]. Using the MDP assessment in

691 malaria patients led us to define the nuances of the inflammatory imbalance associated

692 with P.vivax infection.

693 Conceptually, inflammation is a dynamic process aimed at reestablishing tissue

694 homeostasis. In some infectious diseases, such as malaria, the balance between immune 
medRxiv preprint doi: https://doi.org/10.1101/2021.03.06.21253036; this version posted March 8, 2021. The copyright holder for this preprint (which was not certified by peer review) is the author/funder, who has granted medRxiv a license to display the preprint in perpetuity.

It is made available under a CC-BY-NC 4.0 International license .

695 activation, regulatory cytokine responses and degree of tissue damage is a critical 696 determinant of disease outcomes [42-44]. We explored the dynamicity of the P.vivax 697 infection using the Spearman correlation matrices [24,25,39,45], and found a higher 698 density of correlations among the participants with symptomatic malaria, with 699 predominance of positive correlation among the degree of perturbation of the 700 biomarkers. Despite that, in participants with symptomatic malaria, the degree of CCL2 701 perturbation exhibited two negative correlations, vs. IL-6 and TNF- $\alpha$. Moreover, ALT 702 was the top node in the matrix calculated for symptomatic malaria, highlighting the 703 relevance of liver inflammatory reaction in P.vivax infection [46,47]. Importantly, 704 different from our previous publication using absolute concentration values of 705 inflammatory markers, where we had identified a highest number of correlations in 706 matrices from asymptomatic patients [39], here, by imputing MDP values instead, we 707 found that this group of participants exhibit the lowest network density, suggesting that 708 the absence of symptoms in response to $P$. vivax is associated with a potential 709 uncoupling of the perturbed inflammatory response, probably due to lack of immune 710 activation in peripheral blood. A curious finding was the relative dissociation between 711 tissue inflammatory damage markers and immune factors. This dissociation argues that, 712 except for the liver, the symptoms caused by P.vivax are strongly associated with the 713 cytokine storm in response to infection and may be also linked to local tissue reaction, 714 assessed by measuring levels of liver transaminases for example, but without direct 715 interaction between these MDP levels. This dissociation can be a consequence of the 716 immune evasion mechanisms presented by the parasite, which alter the red blood cell 717 (RBC) structure through expression and export of molecules encoded by plasmodium 718 genome [48]. The interaction between the changed RBC and the host immune cells 719 hinders the plasmodium recognition and enables the tissue damage directly mediated by 720 the pathogen.

721 Epidemiological aspects have largely been described to influence clinical presentation 722 and outcomes in malaria [7,30,31,48]. Many these effects are also related to the profile 723 of the immune response. In continuous exposure to P.vivax, reflected throughout time 724 living in endemic area and age, the host develops clinical immunity against 725 Plasmodium. Still, a controlled inflammatory activation can limit the parasite burden [7] 726 without major perturbations in homeostasis, dampening symptomatology. Here, we 727 showed that repetitive $P$. vivax infection in the past gradually mitigates the 
medRxiv preprint doi: https://doi.org/10.1101/2021.03.06.21253036; this version posted March 8, 2021. The copyright holder for this preprint (which was not certified by peer review) is the author/funder, who has granted medRxiv a license to display the preprint in perpetuity. It is made available under a CC-BY-NC 4.0 International license .

728 inflammatory activation in later infection episodes. The indications of this phenomenon 729 are several. First, we found a robust negative correlation between the time living in an 730 endemic area and the MDP values for all markers measured, except for IL-10 MDP 731 levels. Our results also revealed a higher incidence of symptomatic individuals and 732 fewer symptoms among those who reported living less than ten years in the endemic 733 region. Next, we showed negative correlations between the number of previous malaria 734 episodes and the inflammatory imbalance detected during the current infection, except 735 for, again, IL-10 MDP levels. It is important to note that we found a tendency to 736 decrease systemic inflammation and a lower probability of being highly perturbed in 737 individuals with a greater number of previous malaria episodes.

738 Regarding age, we found that aging is associated with less intense inflammatory 739 activation. Reinforcing the role of hyper-inflammatory status in symptomatology, we 740 demonstrated that the number of symptoms was positively associated with increased 741 MDP levels. Precisely, levels of tissue damage markers, such as AST, ALT, bilirubin, 742 fibrinogen, and creatinine, and the pro-inflammatory markers IL-6 and IFN$743 \gamma$. Additionally, the 'global' systemic inflammation, measured by ssMDP levels, was 744 higher in polysymptomatic participants. Our observations reported here suggest that 745 older individuals who lived for long time in malaria-endemic area and had been exposed 746 to several Plasmodium infections in the past tend to tolerate the current $P$. vivax 747 infection through a decrease in perturbation of all pro-inflammatory and tissue damage 748 markers, and increase in MDP levels of IL-10, which may limit tissue damage and 749 minimize sickness [39-41].

750 Finally, our study tried to dissect the determinants of disease tolerance to $P$. vivax 751 infection. Using data on parasitemia, ssMDP values, and the number of symptoms, we 752 were able to evaluate the interplay between the main factors associated with unfavorable 753 outcomes in an infectious disease: (i) pathogen load; (ii) host response to infection and 754 (iii) clinical consequences of this interaction. Our analysis reveals that the main factor 755 associated with severe cases in $P$. vivax infection was the number of symptoms, 756 demonstrating a robust effect on homeostasis disruption. Of note, these participants 757 exhibited relatively lower parasitemia and ssMDP values, arguing that some persons 758 present severe vivax cases regardless of pathogen burden and inflammatory activation, 759 being little tolerant to infection. In converse, we identified a subgroup of individuals 760 who presented with higher parasitemia and augmented ssMDP values but lower 
medRxiv preprint doi: https://doi.org/10.1101/2021.03.06.21253036; this version posted March 8, 2021. The copyright holder for this preprint (which was not certified by peer review) is the author/funder, who has granted medRxiv a license to display the preprint in perpetuity.

It is made available under a CC-BY-NC 4.0 International license .

761 symptomatology and number of severe malaria cases. This latter group of individuals 762 may be activating the immune response to counteract the parasite load, but without 763 resulting in substantial tissue damage and symptomatology. We also found another 764 group of $P$. vivax-infected study participants who seemed to have controlled infection 765 without inducing substantial inflammatory disturbance, and presented with low 766 parasitemia, lower ssMDP values and few symptoms. Importantly, we found that 767 persons with severe vivax malaria lost the effective control of parasitemia resulting in 768 tissue damage and symptoms, exemplified here by absence of a statistically significant 769 correlation between parasitemia and number of symptoms.

770 Our final results disclosed the determinants of diseases tolerance in P. vivax infection. 771 To do that, we employed networks inputting correlations between degree of molecular 772 perturbation of tissue damage or inflammatory markers with parasitemia and number of 773 symptoms. We described that higher parasitemia in severe vivax malaria was associated 774 with a more robust tissue response, and that the degree of symptomatology was directly 775 related to degree of perturbation in cytokine concentrations. Such scenario may 776 significantly contribute to tissue damage through systemic inflammatory activation and 777 also tissue inflammation, reinforcing our previous results reported above. Nevertheless, 778 in non-severe cases, parasitemia was not associated with MDP of tissue damage 779 markers and the number of symptoms were more linked to systemic inflammatory 780 activation. This latter result reinforces the hypothesis that some patients manage to 781 contain $P$. vivax infection in a balanced fashion, despite presenting some symptoms but 782 without substantial tissue damage. This 'tolerant state' may be associated with 783 epidemiological factors such as those reported here, confirming previously reported 784 results [7].

785 Our study has some limitations. We did not have inflammatory measurements after the 786 malaria therapy, limiting our insights about the systemic inflammation and immune 787 restoration in our participants. Additionally, all our study participants were recruited in 788 Brazil, and additional studies in multiple sites are needed to confirm our findings. 789 Despite these limitations, our study adds to the current knowledge in the field by 790 demonstrating the occurrence of disease tolerance in $P$. vivax malaria and by identifying 791 the major determinants of this phenomenon. 
medRxiv preprint doi: https://doi.org/10.1101/2021.03.06.21253036; this version posted March 8, 2021. The copyright holder for this preprint (which was not certified by peer review) is the author/funder, who has granted medRxiv a license to display the preprint in perpetuity.

It is made available under a CC-BY-NC 4.0 International license .

\section{Acknowledgments}

794 The authors would like to thank Dr Luiz Marcelo Camargo (University of São Paulo)

795 for technical support in field study area; Dr Jorge Clare $\square$ ncio and Dr Daniela Andrade

796 (FIOCRUZ) for technical help with the immunoassays, and Mr Jorge Tolentino, Ms

797 Natali Alexandrino, Mrs Elze Leite, and Mrs Andrezza Kariny for logistic support.

\section{Funding}

799 This work was supported by Financiadora de Estudos e Projetos (FINEP) (grant ward 800 number: 010409605) / Fundo Nacional de Desenvolvimento Científico e Tecnológico

801 (FNDCTCT- Amazônia), Brazil. This study was also financed in part by Coordenacão 802 de Aperfeiçoamento de Pessoal de Nível Superior (CAPES) (Finance Code 001), Brazil.

803 B.B.A. was supported by a grant from the National Institutes of Health (NIH 804 U01AI115940). The work of K.F.F. was supported by CAPES. C.L.V received a 805 fellowship from Conselho Nacional de Desenvolvimento Científico e Tecnológico 806 (CNPq). T.A.C. is a scientific initiation fellow from Fundacão de Amparo à Pesquisa do 807 Estado da Bahia (FAPESB). M.B.A. received a fellowship from the FAPESB. BBA, 808 MBN and MVGL are investigators from CNPq (senior fellowship). The funders had no 809 role in study design, data collection and analysis, decision to publish, or preparation of 810 the manuscript.

\section{Competing interests}

812 The authors have declared that no competing interests exist 
medRxiv preprint doi: https://doi.org/10.1101/2021.03.06.21253036; this version posted March 8, 2021. The copyright holder for this preprint (which was not certified by peer review) is the author/funder, who has granted medRxiv a license to display the preprint in perpetuity.

It is made available under a CC-BY-NC 4.0 International license .

\section{References}

814 1. WHO Global. World malaria report 2019. WHO Regional Office for Africa. 815 2019. Available: https://www.who.int/news-room/fact-sheets/detail/malaria

816 2. da Silva J Jr. National System in Health Surveillance: situation report: Rondônia. 817 Brasília Ministério da Saúde. 2007.

818 3. Gomes AP, Vitorino RR, Costa A de P, Mendonça EG de, Oliveira MG de A, 819 Siqueira-Batista R. Severe Plasmodium falciparum malaria. Rev Bras Ter 820 intensiva. 2011;23: 358-69. doi:10.1590/s0103-507x2011000300015

821 4. Costa FT, Lopes SC, Ferrer M, Leite JA, Martin-Jaular L, Bernabeu M, et al. On cytoadhesion of Plasmodium vivax: raison d'être? Mem Inst Oswaldo Cruz. 2011;106: 79-84. doi:10.1590/S0074-02762011000900010

824

825

826

827

828

829

830

831

832

833

834

5. Val F, Machado K, Barbosa L, Salinas JL, Siqueira AM, Costa Alecrim MG, et al. Respiratory Complications of Plasmodium vivax Malaria: Systematic Review and Meta-Analysis. Am J Trop Med Hyg. 2017;97: 733-743. doi:10.4269/ajtmh.17-0131

6. Cruz LAB, Barral-Netto M, Andrade BB. Distinct inflammatory profile underlies pathological increases in creatinine levels associated with Plasmodium vivax malaria clinical severity. PLoS Negl Trop Dis. 2018;12: e0006306. doi:10.1371/journal.pntd.0006306

7. Andrade BB, Barral-Netto M. Biomarkers for susceptibility to infection and disease severity in human malaria. Mem Inst Oswaldo Cruz. 2011;106 Suppl: 70-8. doi:10.1590/s0074-02762011000900009

835

836

8. Laishram DD, Sutton PL, Nanda N, Sharma VL, Sobti RC, Carlton JM, et al. The complexities of malaria disease manifestations with a focus on asymptomatic malaria. Malar J. 2012;11: 29. doi:10.1186/1475-2875-11-29

838 9. de Mendonça VR, Barral-Netto M. Immunoregulation in human malaria: The challenge of understanding asymptomatic infection. Mem Inst Oswaldo Cruz. 2015;110: 945-955. doi:10.1590/0074-02760150241

10. Shanks GD. Perspective piece tolerance may be more appropriate than immunity when describing chronic malaria infections. Am J Trop Med Hyg. 2019;100: 497-500. doi:10.4269/ajtmh.18-0906

11. Schneider DS, Ayres JS. Two ways to survive infection: what resistance and tolerance can teach us about treating infectious diseases. Nat Rev Immunol. 2008;8: 889-895. doi:10.1038/nri2432

850

13. Medzhitov R, Schneider DS, Soares MP. Disease Tolerance as a Defense 851

12. Sorci G, Faivre B. Inflammation and oxidative stress in vertebrate host-parasite systems. Philos Trans R Soc Lond B Biol Sci. 2009;364: 71-83. doi:10.1098/rstb.2008.0151

Strategy. Science (80- ). 2012;335: 936-941. doi:10.1126/science.1214935 
medRxiv preprint doi: https://doi.org/10.1101/2021.03.06.21253036; this version posted March 8, 2021. The copyright holder for this preprint (which was not certified by peer review) is the author/funder, who has granted medRxiv a license to display the preprint in perpetuity. It is made available under a CC-BY-NC 4.0 International license .

852 14. Ayres JS, Schneider DS. Tolerance of Infections. Annu Rev Immunol. 2012;30: 271-294. doi:10.1146/annurev-immunol-020711-075030

15. Gozzelino R, Andrade BB, Larsen R, Luz NF, Vanoaica L, Seixas E, et al. Metabolic adaptation to tissue iron overload confers tolerance to malaria. Cell Host Microbe. 2012;12: 693-704. doi:10.1016/j.chom.2012.10.011

16. Reyburn H. Association of Transmission Intensity and Age With Clinical Manifestations and Case Fatality of Severe Plasmodium falciparum Malaria. JAMA. 2005;293: 1461. doi:10.1001/jama.293.12.1461

17. Snow RW, Guerra CA, Noor AM, Myint HY, Hay SI. The global distribution of clinical episodes of Plasmodium falciparum malaria. Nature. 2005;434: 214-217. doi:10.1038/nature03342

863

18. Gonçalves BP, Huang C-Y, Morrison R, Holte S, Kabyemela E, Prevots DR, et al. Parasite Burden and Severity of Malaria in Tanzanian Children. N Engl J Med. 2014;370: 1799-1808. doi:10.1056/NEJMoa1303944

866

19. Vallejo AF, Read RC, Arevalo-Herrera M, Herrera S, Elliott T, Polak ME. Malaria systems immunology: Plasmodium vivax induces tolerance during primary infection through dysregulation of neutrophils and dendritic cells. $\mathbf{J}$

20. Ademolue TW, Aniweh Y, Kusi KA, Awandare GA. Patterns of inflammatory responses and parasite tolerance vary with malaria transmission intensity. Malar J. 2017;16: 1-13. doi:10.1186/s12936-017-1796-x

21. Ramos S, Carlos AR, Sundaram B, Jeney V, Ribeiro A, Gozzelino R, et al. Renal control of disease tolerance to malaria. Proc Natl Acad Sci U S A. 2019;116: 5681-5686. doi:10.1073/pnas.1822024116

875

22. Wang A, Huen SC, Luan HH, Baker K, Rinder H, Booth CJ, et al. Glucose metabolism mediates disease tolerance in cerebral malaria. Proc Natl Acad Sci U S A. 2018;115: 11042-11047. doi:10.1073/pnas.1806376115

23. Vandermosten L, Pham TT, Knoops S, De Geest C, Lays N, Van der Molen K, et al. Adrenal hormones mediate disease tolerance in malaria. Nat Commun. 2018;9. doi:10.1038/s41467-018-06986-5

882

883

884

885

24. Vinhaes CL, Arriaga MB, de Almeida BL, Oliveira J V, Santos CS, Calcagno JI, et al. Newborns With Zika Virus-Associated Microcephaly Exhibit Marked Systemic Inflammatory Imbalance. J Infect Dis. 2020;222: 670-680. doi:10.1093/infdis/jiaa197

25. Vinhaes CL, Cruz LAB, Menezes RC, Carmo TA, Arriaga MB, Queiroz ATL, et al. Chronic Hepatitis B Infection Is Associated with Increased Molecular Degree of Inflammatory Perturbation in Peripheral Blood. Viruses. 2020;12. doi:10.3390/v12080864

890 
medRxiv preprint doi: https://doi.org/10.1101/2021.03.06.21253036; this version posted March 8, 2021. The copyright holder for this preprint (which was not certified by peer review) is the author/funder, who has granted medRxiv a license to display the preprint in perpetuity.

It is made available under a CC-BY-NC 4.0 International license .

892

893

894

895

896

897

898

899

900

901

902

903

904

905

906

907

908

909

910

911

912

913

914

915

916

917

918

919

920

921

922

923

924

925

926

927

928

929

930

931

932

933 markers associated with tuberculosis reveals distinct disease profiles between Indian and Chinese populations. Sci Rep. 2019;9: 8002. doi:10.1038/s41598-01944513-8

27. Vinhaes CL, Oliveira-de-Souza D, Silveira-Mattos PS, Nogueira B, Shi R, Wei $\mathrm{W}$, et al. Changes in inflammatory protein and lipid mediator profiles persist after antitubercular treatment of pulmonary and extrapulmonary tuberculosis: A $\begin{array}{llll}\text { prospective cohort study. Cytokine. 2019;123: } 154759 . & \text {. }\end{array}$ doi:10.1016/j.cyto.2019.154759

28. Vinhaes CL, Teixeira RS, Monteiro-Júnior JAS, Tibúrcio R, Cubillos-Angulo $\mathrm{JM}$, Arriaga MB, et al. Hydroxyurea treatment is associated with reduced degree of oxidative perturbation in children and adolescents with sickle cell anemia. Sci Rep. 2020;10: 18982. doi:10.1038/s41598-020-76075-5

29. Andrade BB, Santos CJN, Camargo LM, Souza-Neto SM, Reis-Filho A, Clarêncio J, et al. Hepatitis B infection is associated with asymptomatic malaria in the Brazilian Amazon. PLoS One. 2011;6: e19841. doi:10.1371/journal.pone.0019841

30. Baird JK. Age-dependent characteristics of protection v. susceptibility to Plasmodium falciparum. Ann Trop Med Parasitol. 1998;92: 367-90. doi:10.1080/00034989859366

31. Baird JK, Jones TR, Danudirgo EW, Annis BA, Bangs MJ, Basri H, et al. Agedependent acquired protection against Plasmodium falciparum in people having two years exposure to hyperendemic malaria. Am J Trop Med Hyg. 1991;45: 6576. doi:10.4269/ajtmh.1991.45.65

32. Galatas B, Bassat Q, Mayor A. Malaria Parasites in the Asymptomatic: Looking for the Hay in the Haystack. Trends Parasitol. 2016;32: 296-308. doi:10.1016/j.pt.2015.11.015

33. Oliveira-de-Souza D, Vinhaes CL, Arriaga MB, Kumar NP, Queiroz ATL, Fukutani KF, et al. Aging increases the systemic molecular degree of inflammatory perturbation in patients with tuberculosis. Sci Rep. 2020;10: 11358. doi:10.1038/s41598-020-68255-0

34. Barretto JR, Boa-Sorte N, Vinhaes CL, Malta-Santos H, Rebouças-Silva J, Ramos CF, et al. Heightened Plasma Levels of Transforming Growth Factor Beta (TGF- $\beta$ ) and Increased Degree of Systemic Biochemical Perturbation Characterizes Hepatic Steatosis in Overweight Pediatric Patients: A CrossSectional Study. Nutrients. 2020;12. doi:10.3390/nu12061650

35. Andrade BB, Reis-Filho A, Souza-Neto SM, Clarêncio J, Camargo LMA, Barral A, et al. Severe Plasmodium vivax malaria exhibits marked inflammatory imbalance. Malar J. 2010;9: 13. doi:10.1186/1475-2875-9-13

36. Mendonça VRR, Souza LCL, Garcia GC, Magalhães BML, Lacerda MVG, Andrade BB, et al. DDX39B (BAT1), TNF and IL6 gene polymorphisms and association with clinical outcomes of patients with Plasmodium vivax malaria. Malar J. 2014;13: 278. doi:10.1186/1475-2875-13-278 
medRxiv preprint doi: https://doi.org/10.1101/2021.03.06.21253036; this version posted March 8, 2021. The copyright holder for this preprint (which was not certified by peer review) is the author/funder, who has granted medRxiv a license to display the preprint in perpetuity. It is made available under a CC-BY-NC 4.0 International license .

934 37. Hojo-Souza NS, Pereira DB, de Souza FSH, de Oliveira Mendes TA, Cardoso

935

936

937

938

939

940

941

942

943

944

945

946

947

948

949

950

951

952

953

954

955

956

957

958

959

960

961

962

963

964

965

966

967

968

969

970

971

972

973

974

MS, Tada MS, et al. On the cytokine/chemokine network during Plasmodium vivax malaria: new insights to understand the disease. Malar J. 2017;16: 42. doi:10.1186/s12936-017-1683-5

38. Raza A, Ghanchi NK, Sarwar Zubairi A bin, Raheem A, Nizami S, Beg MA. Tumor necrosis factor $-\alpha$, interleukin-10, intercellular and vascular adhesion molecules are possible biomarkers of disease severity in complicated Plasmodium vivax isolates from Pakistan. PLoS One. 2013;8: e81363. doi:10.1371/journal.pone.0081363

39. Mendonça VRR, Queiroz ATL, Lopes FM, Andrade BB, Barral-Netto M. Networking the host immune response in Plasmodium vivax malaria. Malar J. 2013;12: 69. doi:10.1186/1475-2875-12-69

40. Kurtzhals JA, Adabayeri V, Goka BQ, Akanmori BD, Oliver-Commey JO, Nkrumah FK, et al. Low plasma concentrations of interleukin 10 in severe malarial anaemia compared with cerebral and uncomplicated malaria. Lancet (London, England). 1998;351: 1768-72. doi:10.1016/S0140-6736(97)09439-7

41. May J, Lell B, Luty AJ, Meyer CG, Kremsner PG. Plasma interleukin-10:Tumor necrosis factor (TNF)-alpha ratio is associated with TNF promoter variants and predicts malarial complications. J Infect Dis. 2000;182: 1570-3. doi: $10.1086 / 315857$

42. Riley EM, Wahl S, Perkins DJ, Schofield L. Regulating immunity to malaria. Parasite Immunol. 28: 35-49. doi:10.1111/j.1365-3024.2006.00775.x

43. Langhorne J, Albano FR, Hensmann M, Sanni L, Cadman E, Voisine C, et al. Dendritic cells, pro-inflammatory responses, and antigen presentation in a rodent malaria infection. Immunol Rev. 2004;201: 35-47. doi:10.1111/j.01052896.2004.00182.x

44. Gonçalves RM, Scopel KKG, Bastos MS, Ferreira MU. Cytokine balance in human malaria: does Plasmodium vivax elicit more inflammatory responses than Plasmodium falciparum? PLoS One. 2012;7: e44394. doi:10.1371/journal.pone.0044394

45. Vinhaes CL, Sheikh V, De-Souza DO, Wang J, Rupert A, Roby G, et al. An inflammatory composite score predicts mycobacterial IRIS in people with HIV and severe lymphopenia: A prospective international cohort study. J Infect Dis. 2020. doi:10.1093/infdis/jiaa484

46. Odedra A, Webb L, Marquart L, Britton LJ, Chalon S, Moehrle JJ, et al. Liver Function Test Abnormalities in Experimental and Clinical Plasmodium vivax Infection. Am J Trop Med Hyg. 2020. doi:10.4269/ajtmh.20-0491

47. Putrianti ED, Schmidt-Christensen A, Heussler V, Matuschewski K, Ingmundson A. A Plasmodium cysteine protease required for efficient transition from the liver infection stage. PLoS Pathog. 2020;16: e1008891. doi:10.1371/journal.ppat.1008891 
medRxiv preprint doi: https://doi.org/10.1101/2021.03.06.21253036; this version posted March 8, 2021. The copyright holder for this preprint (which was not certified by peer review) is the author/funder, who has granted medRxiv a license to display the preprint in perpetuity.

It is made available under a CC-BY-NC 4.0 International license .

975 48. Yui K, Inoue S-I. Host-pathogen interaction in the tissue environment during Plasmodium blood-stage infection. Parasite Immunol. 2021;43: e12763. doi:10.1111/pim.12763

49. Cucunubá ZM, Guerra AP, Rahirant SJ, Rivera JA, Cortés LJ, Nicholls RS. Asymptomatic Plasmodium spp. infection in Tierralta, Colombia. Mem Inst Oswaldo Cruz. 2008;103: 668-73. doi:10.1590/s0074-02762008000700007

50. Andrade BB, Rocha BC, Reis-Filho A, Camargo LMA, Tadei WP, Moreira LA, et al. Anti-Anopheles darlingi saliva antibodies as marker of Plasmodium vivax infection and clinical immunity in the Brazilian Amazon. Malar J. 2009;8: 121.

983

984 doi:10.1186/1475-2875-8-121

985

986

987

988

989

51. Andrade BB, Araújo-Santos T, Luz NF, Khouri R, Bozza MT, Camargo LMA, et al. Heme impairs prostaglandin E2 and TGF-beta production by human mononuclear cells via $\mathrm{Cu} / \mathrm{Zn}$ superoxide dismutase: insight into the pathogenesis of severe malaria. J Immunol. 2010;185: 1196-204. doi:10.4049/jimmunol.0904179

52. Andrade BB, Reis-Filho A, Barros AM, Souza-Neto SM, Nogueira LL, Fukutani $\mathrm{KF}$, et al. Towards a precise test for malaria diagnosis in the Brazilian Amazon: comparison among field microscopy, a rapid diagnostic test, nested PCR, and a computational expert system based on artificial neural networks. Malar J. 2010;9: 117. doi:10.1186/1475-2875-9-117

53. Andrade BB, Reis-Filho A, Souza-Neto SM, Raffaele-Netto I, Camargo LMA, Barral A, et al. Plasma superoxide dismutase-1 as a surrogate marker of vivax malaria severity. PLoS Negl Trop Dis. 2010;4: e650. doi:10.1371/journal.pntd.0000650

54. Mendonça VRR, Luz NF, Santos NJG, Borges VM, Gonçalves MS, Andrade BB, et al. Association between the haptoglobin and heme oxygenase 1 genetic profiles and soluble CD163 in susceptibility to and severity of human malaria. Infect Immun. 2012;80: 1445-54. doi:10.1128/IAI.05933-11 
medRxiv preprint doi: https://doi.org/10.1101/2021.03.06.21253036; this version posted March 8, 2021. The copyright holder for this preprint (which was not certified by peer review) is the author/funder, who has granted medRxiv a license to display the preprint in perpetuity.

It is made available under a CC-BY-NC 4.0 International license .

\section{Supporting Information}

1006 S1 File. Raw data used in the analyses.

1007 S1 Table. Characteristics of the study participants.

1008 S1 Figure. Epidemiological and immune factors associated with symptomatic

1009 Plasmodium vivax malaria.

1010 S2 Figure. Determinants of the global degree of perturbation.

1011 S3 Figure. Influences of age and number of previous episodes in the inflammatory 1012 imbalance in Plasmodium vivax infection. 


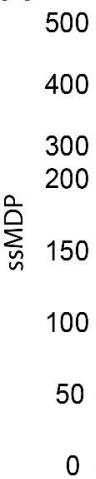

B
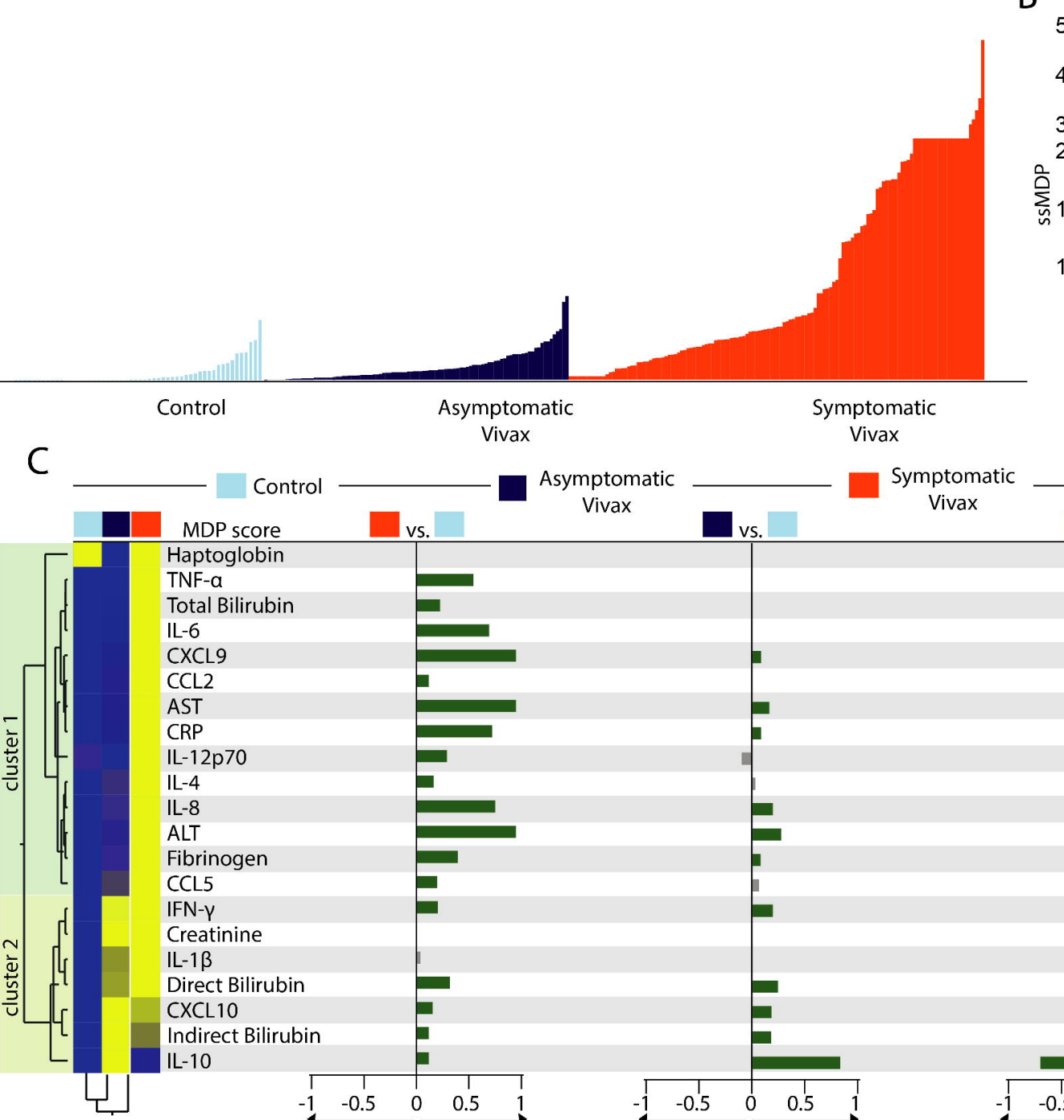

Control
Asymptomatic

Vivax
Symptomatic

Vivax
$P<0.001$

$\mathrm{P}<0.001$

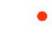

Control Vivax

Vivax

Asymptomatic

Symptomatic
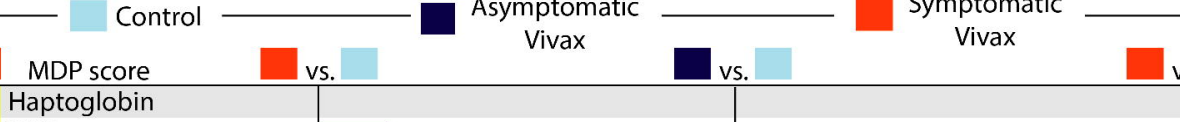

TNF-a

Total Bilirubin

IL-6

CXCL9

CCL2

AST

CRP

IL-12p70

IL-4

IL-8

ALT

Fibrinogen

CCL5

IFN- $\gamma$

Creatinine

IL-1 $\beta$

Direct Bilirubin

CXCL10

Indirect Bilirubin

IL-10
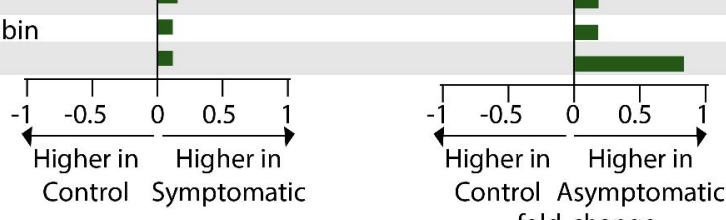

fold-change

SD from mean

$-2$ 
$A$

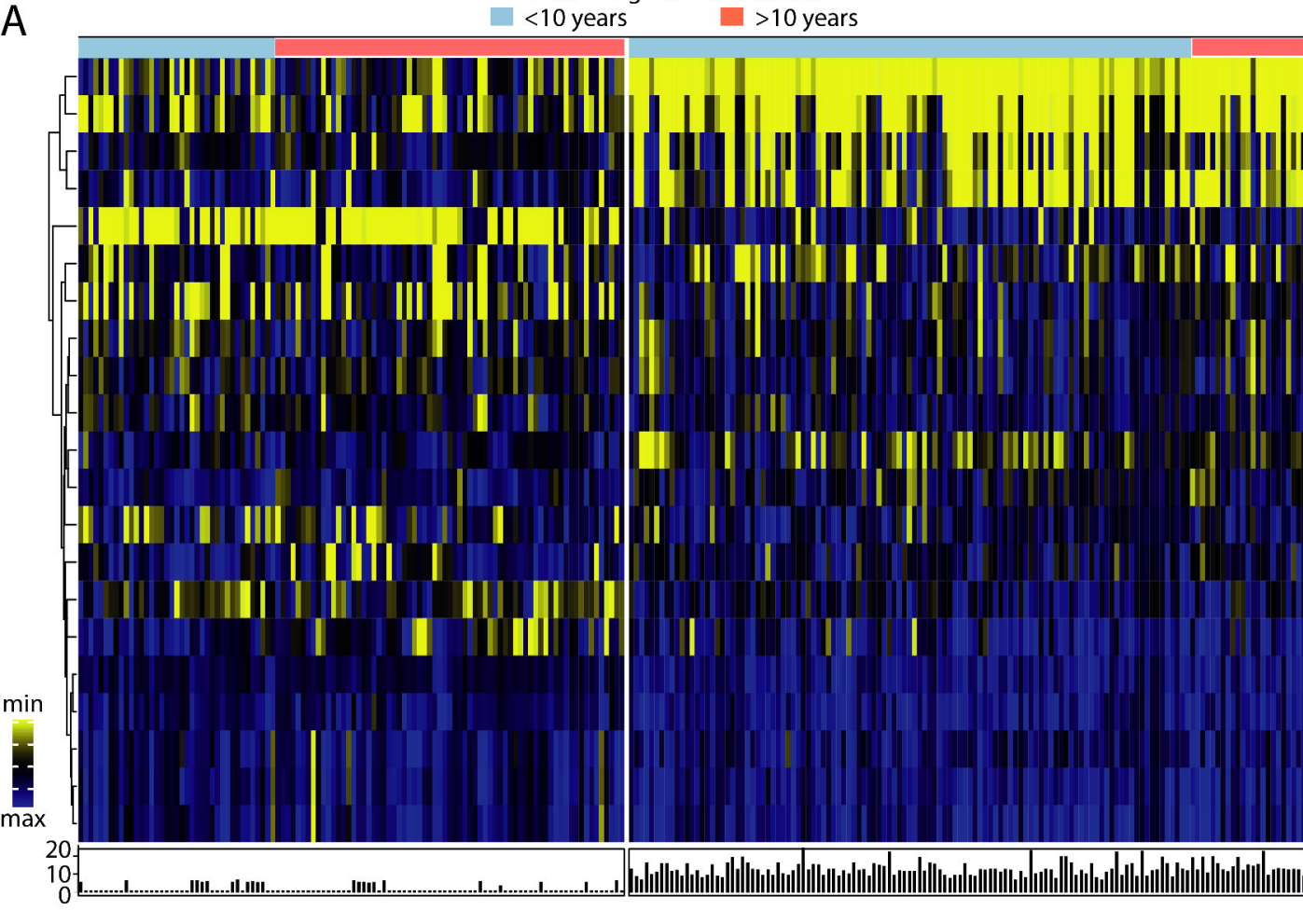

Asymptomatic malaria
Time living in endemic area vs.

ALT

\section{AST}

IL-8 CXCL9

IL-10

Direct Bilirubin

Total Bilirubin

Indirect Bilirubin

Fibrinogen

IL-6

TNF-a

IFN- $\gamma$

IL-12p70

Haptoglobin

Creatinine

CXCL10

IL-1 $\beta$

IL-4

CCL5

$\mathrm{CCL} 2$

Parasitemia
B

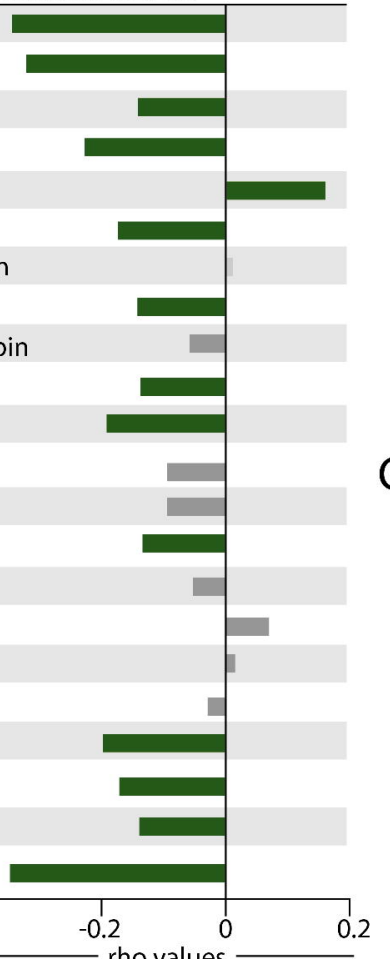

Chi-square $P<0.001$

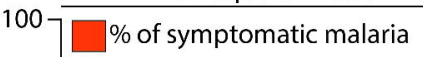

80- $\%$ of asymptomatic malaria

$\frac{<10 \text { years }>10 \text { years }}{\text { Years living in endemic area }}$

${ }_{18}$

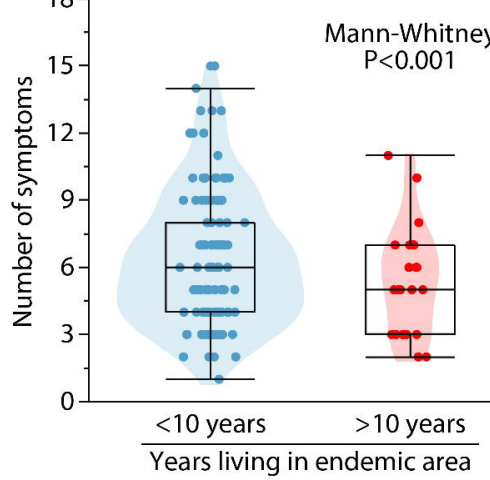



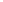
Sweating Headache Myalgia Arthralgia Nausea

Vomit Hyporexia Disorientation

Palpitations Dizziness Abdominal pain Diarrhea Pallor

Parasitemia Age

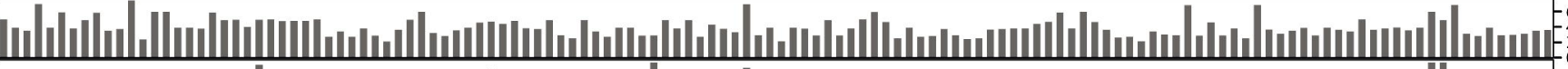

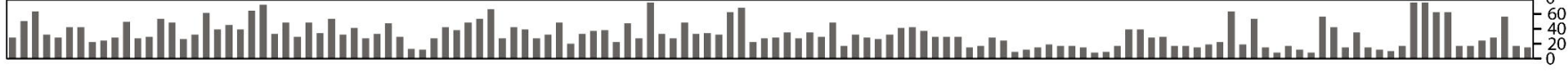

B

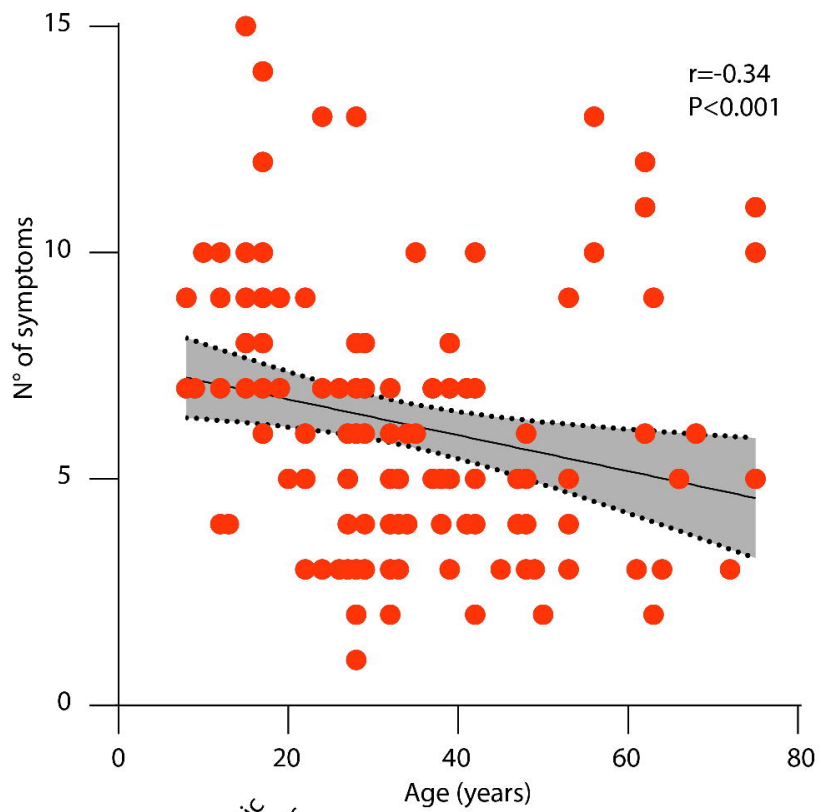

C

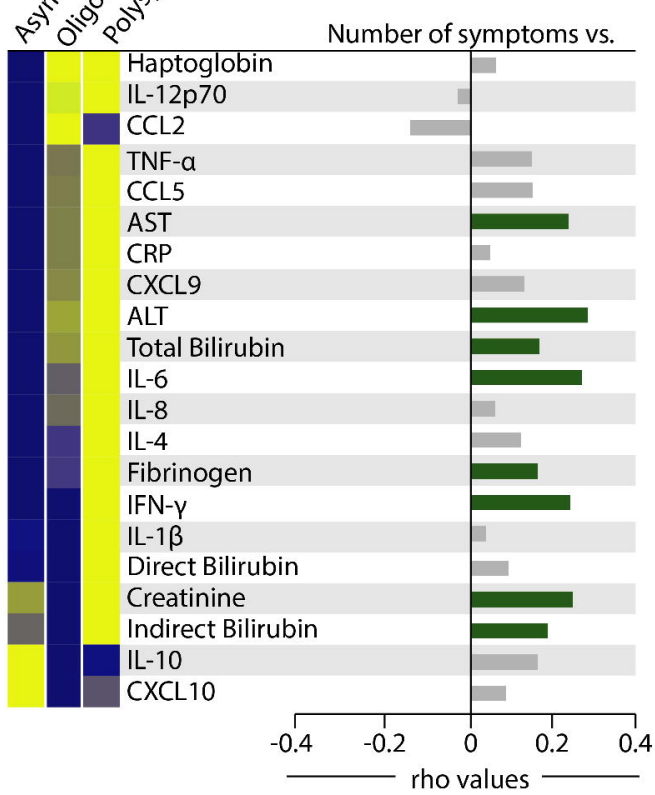

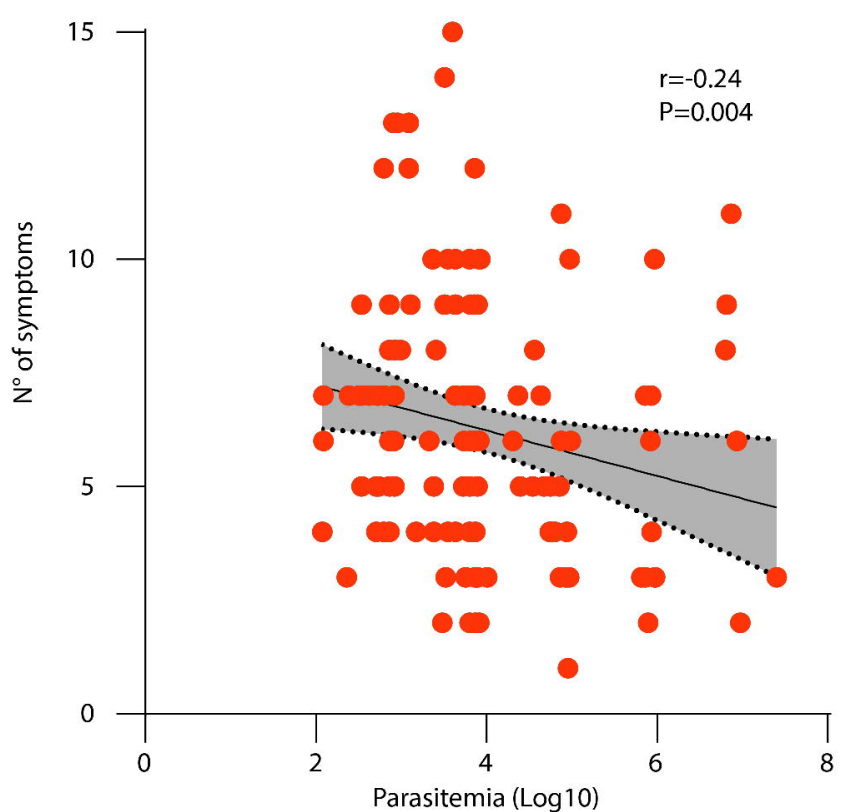

D

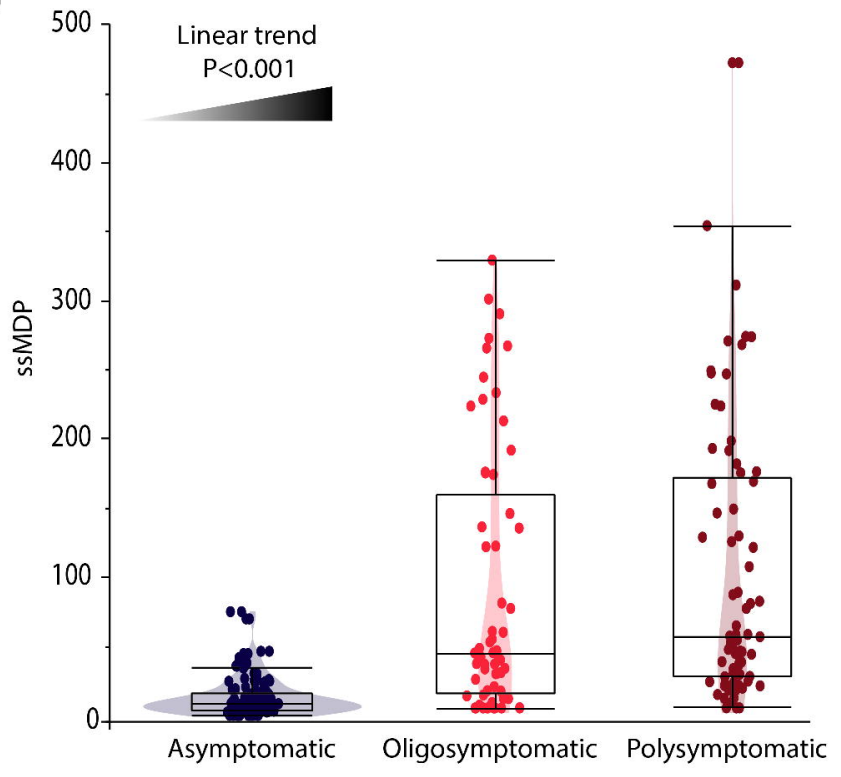




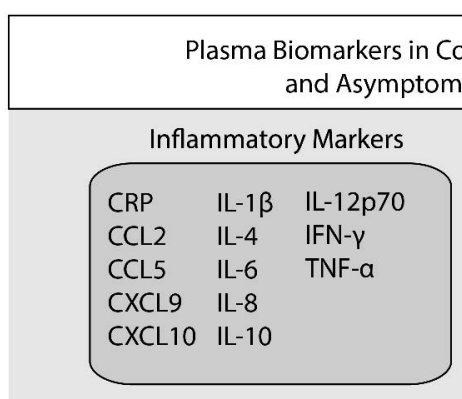

$\begin{array}{ll}\text { ALT } & \text { Direct Bilirubin } \\ \text { AST } & \text { Indirect Bilirruin } \\ \text { Creatinine } & \text { Fibrinogen } \\ \text { Haptoglobin }\end{array}$

Haptoglobin
C.

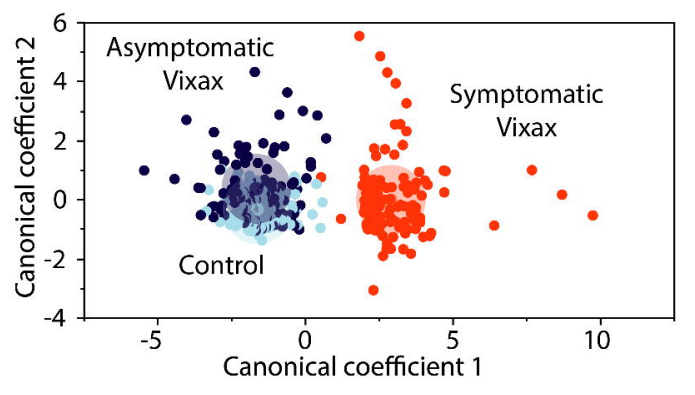

Predicted Count Tissue Damage Markers

\begin{tabular}{|lccc|}
\hline & Control & Asymp & Symp \\
Control & 92 & 36 & 0 \\
Asymp & 50 & 57 & 1 \\
Symp & 0 & 1 & 133 \\
\hline
\end{tabular}

Asymptomatic Vivax vs.

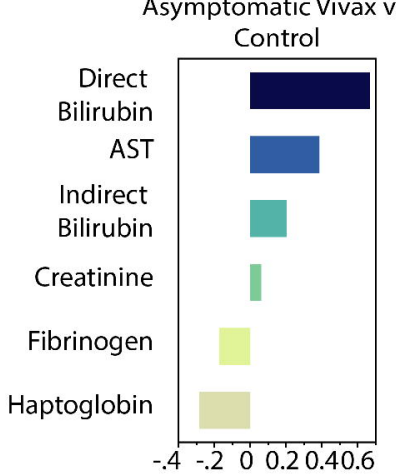

Symptomatic Vivax vs.

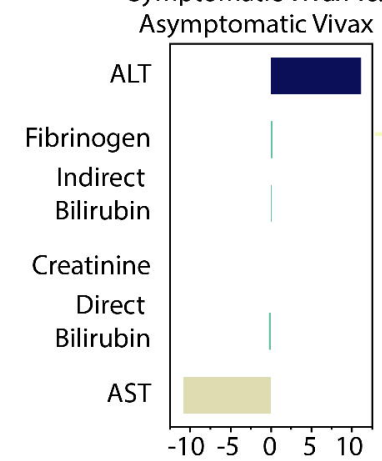

All Markers Canonical Model

B

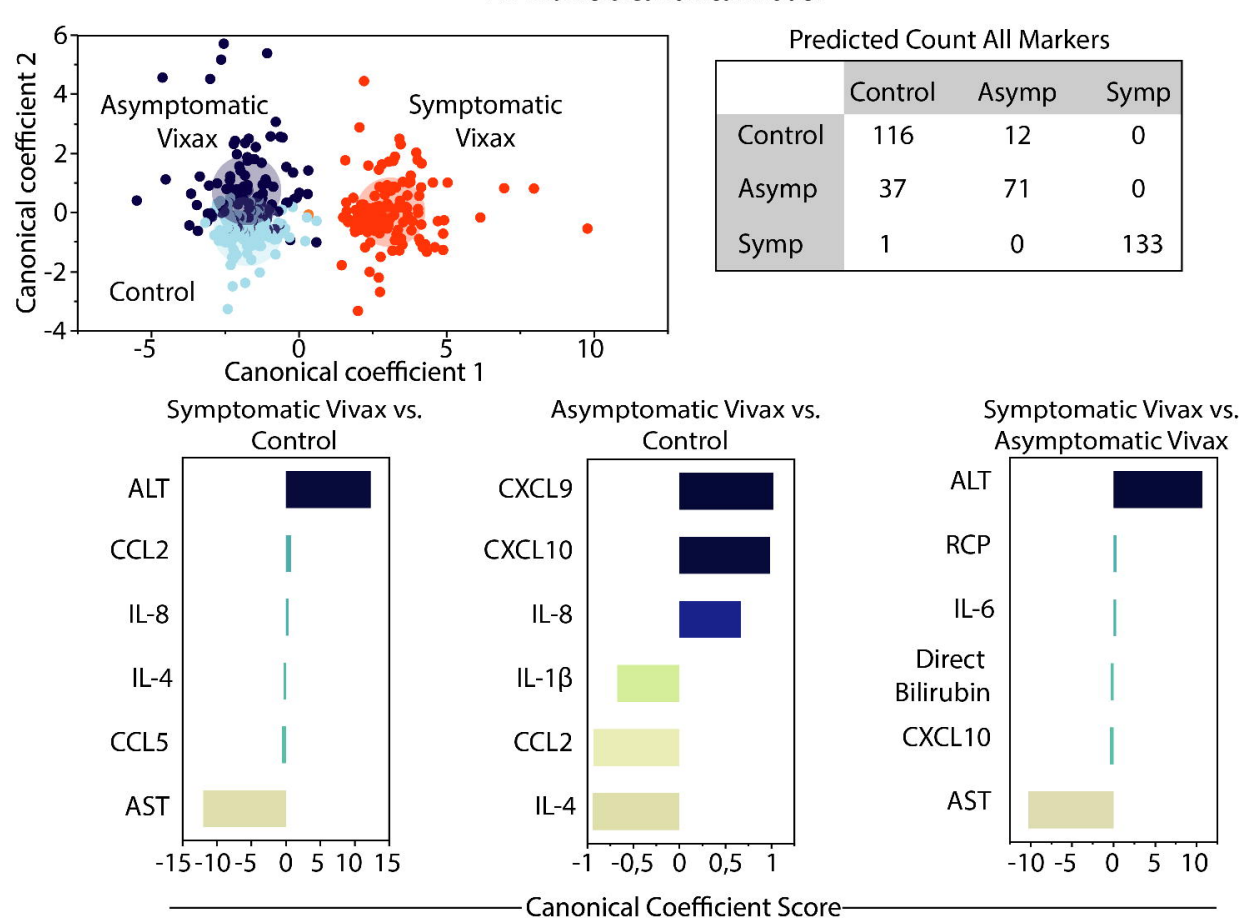

D

Inflammatory Canonical Model
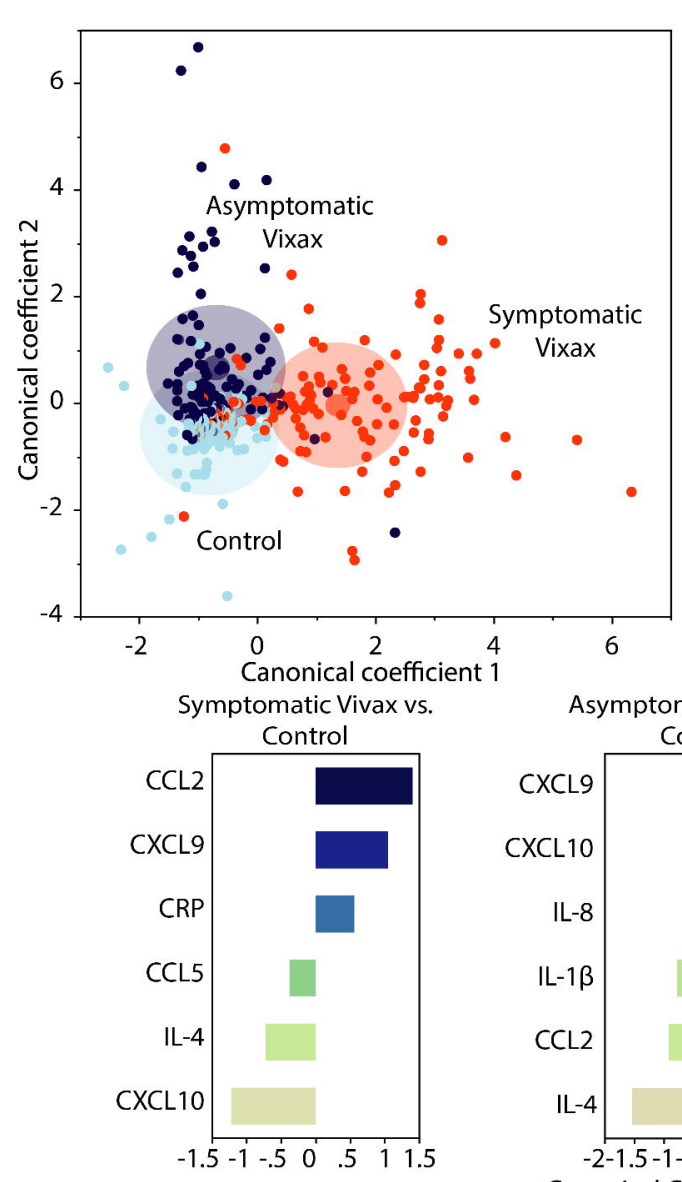

Predicted Count Inflammatory Markers
\begin{tabular}{|lccc|}
\hline & Control & Asymp & Symp \\
Control & 120 & 8 & 0 \\
Asymp & 35 & 67 & 6 \\
Symp & 29 & 9 & 96 \\
\hline
\end{tabular}

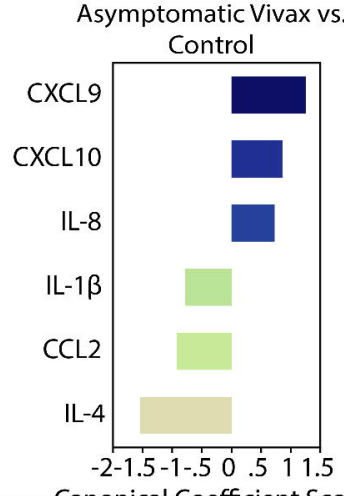

Symptomatic Vivax vs.

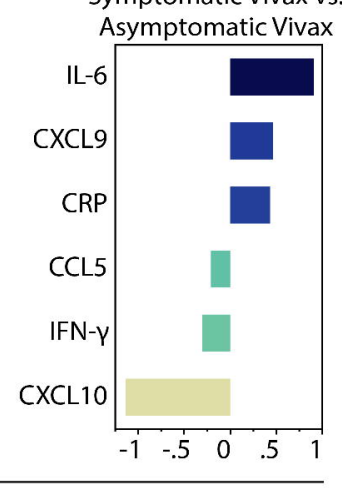



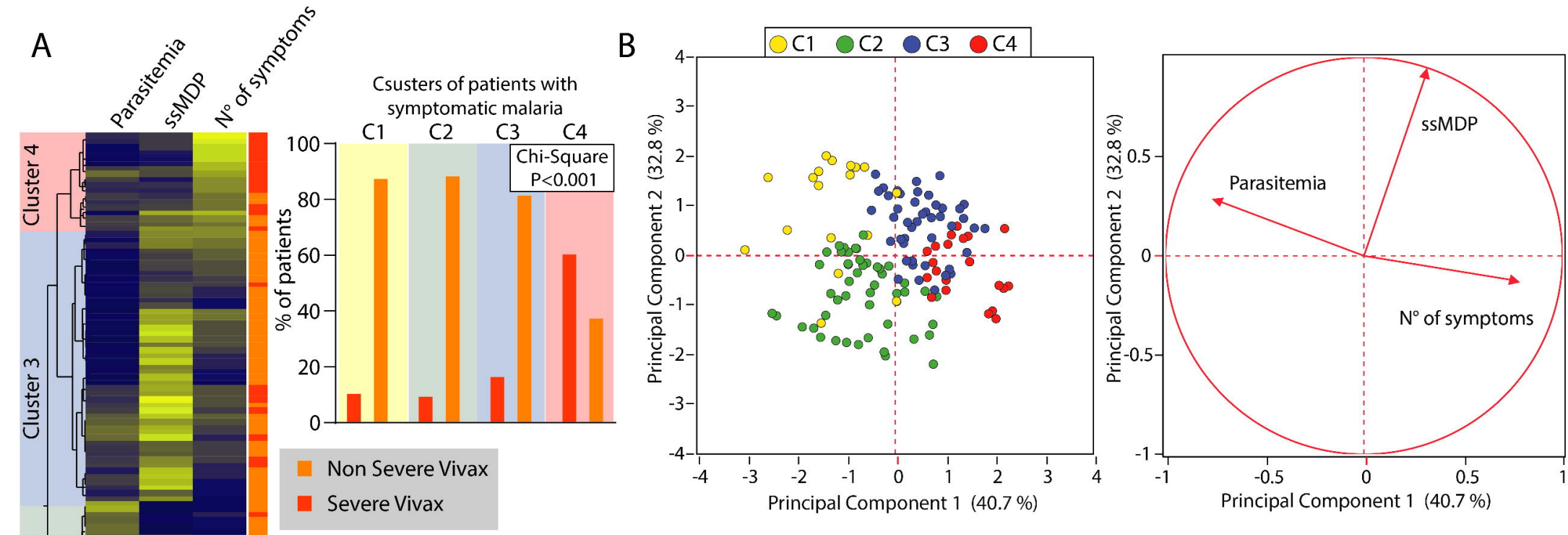

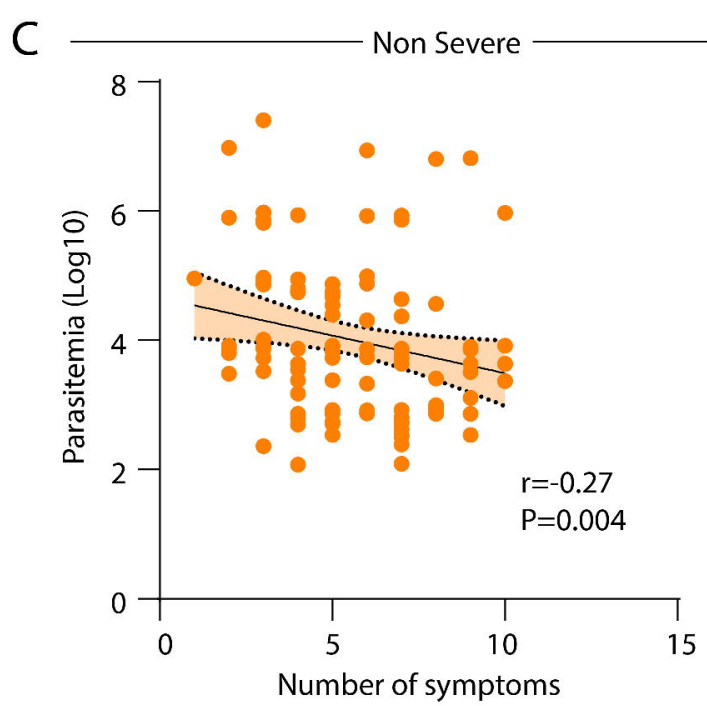

D

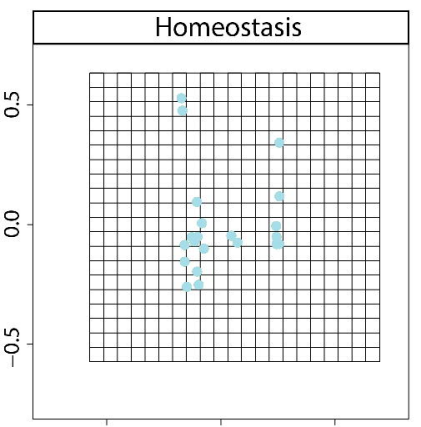

$\begin{array}{lll}-0.5 & 0.0 & 0.5\end{array}$

space-time brane: arbitrary units to define the homeostasis as a defined plane
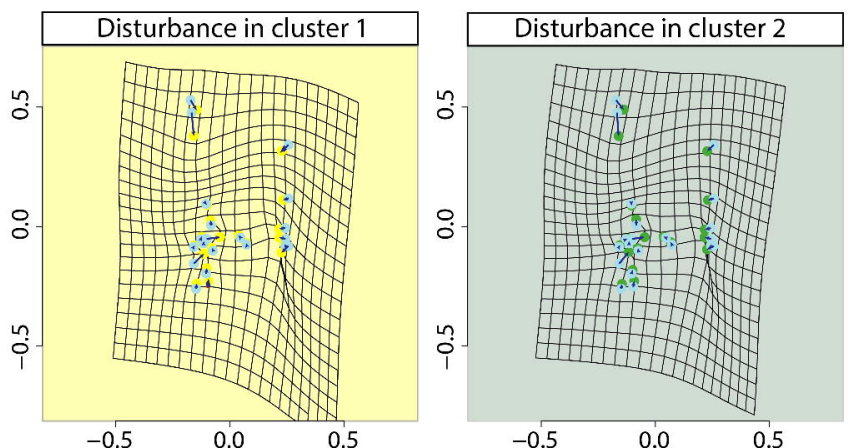

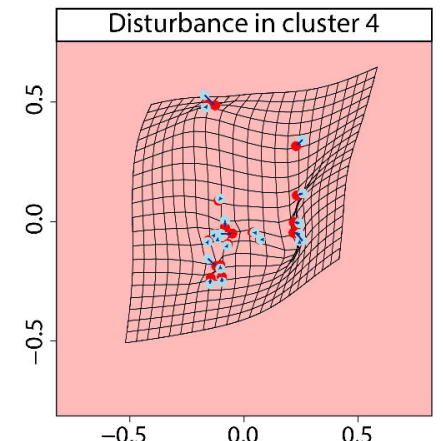

Tolerance to Plasmodium vivax infection 


\begin{tabular}{|c|c|}
\hline $\begin{array}{c}\text { Inflammtory } \\
\text { Markers }\end{array} \quad$ Parasitemia & $\begin{array}{c}\text { Tissue Damage } \\
\text { Markers }\end{array}$ \\
\hline
\end{tabular}

No Tissue Damage Markers was

Associated with Parasitemia in

IL-1 $\beta$

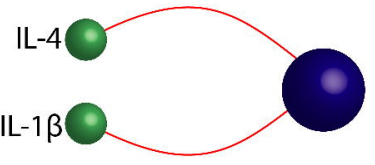

Participants with Non-severe Malaria
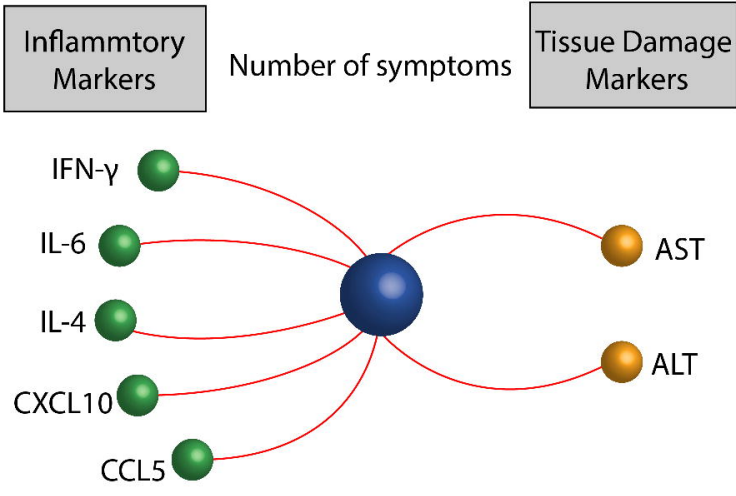
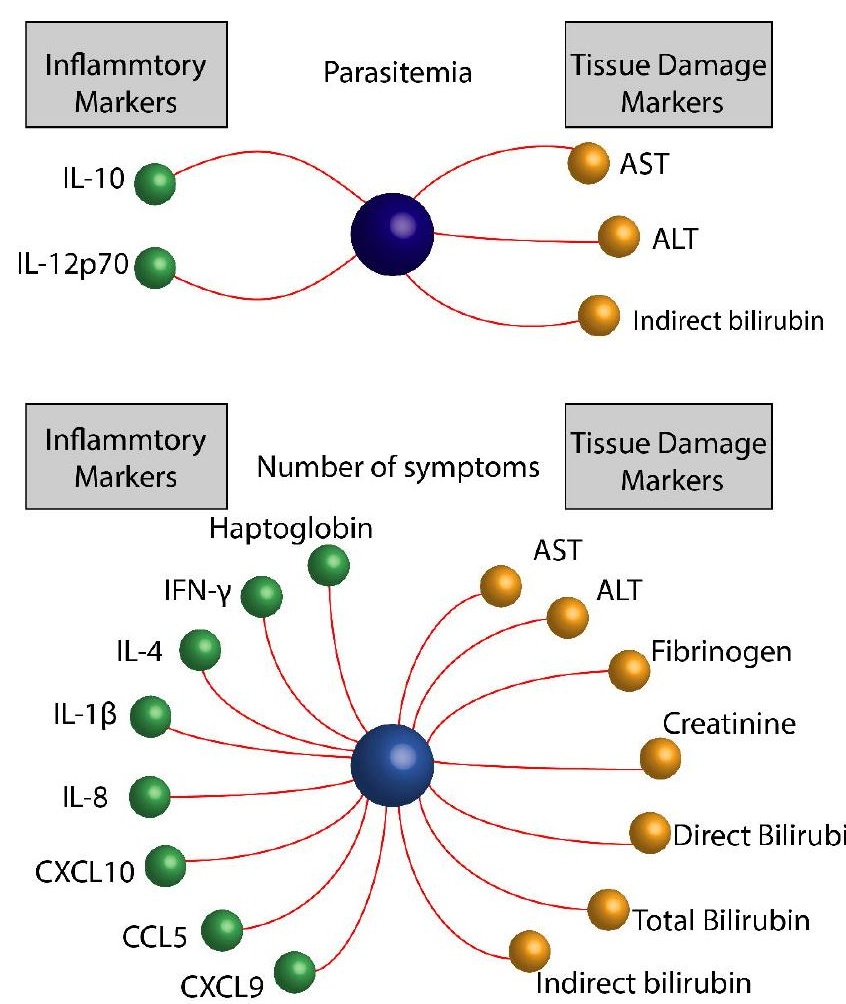